Article

\title{
Construction Process Technical Impact Factors on Degradation of the External Thermal Insulation Composite System
}

\author{
Virgo Sulakatko ${ }^{1,2, *(1)}$ and Frank U. Vogdt ${ }^{2}$ \\ 1 Department of Civil Engineering and Architecture, Tallinn University of Technology, 19068 Tallinn, Estonia \\ 2 Institute of Civil Engineering, Technical University of Berlin, 10623 Berlin, Germany; bauphysik@tu-berlin.de \\ * Correspondence: virgo.sulakatko@taltech.ee
}

Received: 16 September 2018; Accepted: 20 October 2018; Published: 26 October 2018

check for updates

\begin{abstract}
The European climate strategy has encouraged the usage of the External Thermal Insulation Composite System (ETICS) to increase the energy efficiency of external building envelopes. This externally and relatively easily applicable façade solution must meet various technical requirements. This paper develops a technical severity evaluation model of on-site construction activities of ETICS to prioritize the risks of the construction process. The model can be used independently by any stakeholder of the construction process. The relevance of the activities is assessed with the Failure Mode Effects Analysis method. The model weights the impact of the essential technical requirements and simulates an integrated weighted technical severity value, which is derived from the analysis of experts' judgments validated with the non-parametric Friedman's test. The data collection for probability of occurrence and difficulty of detectability follows the Delphi technique to quantify the opinions of a group. The simulation, conducted on 103 degradation factors, shows that the on-site construction activities of ETICS strongly influence the decrease in the technical resilience of long-term durability, mechanical resistance, and stability, as well as the ability to bypass tensions. The highest risk is detected by the shortcomings in the layers of substrate, reinforcement, adhesive, and additional details.
\end{abstract}

Keywords: External Thermal Insulation Composite System; ETICS; quality control; durability; building defects

\section{Introduction}

European countries need to refurbish existing dwellings and increase their quality as well as energy efficiency, as 70\% of the housing stock in the European Union was built before 1980 [1]. It is expected that the life-span for multi-story dwellings is between 50 and 70 years, which emphasizes the need for imminent updates. The energy efficiency requirements have increased the usage of the External Thermal Insulation Composite System (ETICS) as a refurbishment possibility to extend the service life of the external shell [2,3]. Due to the increased interest in this construction technology, the durability of the ETICS, as well as the pathology of the degradation signs, has become a popular research subject.

The ETICS has many advantages, which have made it a favourable façade solution and increased its usage in European countries. This complex system is a combination of different construction materials in several layers, all having specific requirements as well as application methods. Each layer of the system is designed to provide particular value and has a significant role. Possible deterioration causes include poor design, unsuitable usage of building materials, or on-site construction technology inadequacies [4]. Institut für Bauforschung [5] revealed in their study that construction activities cause $66 \%$ of the defects in the ETICS, which have failed to achieve energy performance requirements. 
Neumann [6], in turn, stated that three-quarters of the on-site activities are avoidable. These statements raise the question as to why the number of occurring defects is so high, as the relevance, as well as the main causes of degradation, are known to the industry.

Construction influences the resilience as well as the future deterioration of the ETICS in each layer. As each layer has a different purpose, the relevance to the system is diverse. The research conducted in the field of the quality of the ETICS rationalizes the specific reasons for degradation in silos. These silos have caused a situation where a large number of reasons for degradation have been identified, but it is impossible to prioritize their impact on the ETICS system as a whole. Amaro et al. [7] and Silva [8] approached the problem from the maintenance point of view, developing a predictive maintenance assessment model. Their top-down approach detects deterioration and connects multiple possible causes. To investigate the cause for visible deterioration with in situ analysis, a destructive test is most often required. A number of conducted destructive tests have been discussed $[6,9,10]$, as well as reconstructed in laboratory conditions [11-13]. Additionally, the behavior of deviations of specific components has been studied in isolation, which determined the pathology routes to consider. These routes include the change in mechanical properties through added kneading water to the mixture [14], freezing or drying of the mixture caused by weather effects while the façade is insufficiently covered [12,14,15], increased vapor resistance due to increased thickness of the mortar [16], or increased thermal conductivity through the gaps between insulation materials [17]. These and many other degradation factors are included in our study in a single framework to enable the setting of priorities during the construction process.

The research problem is approached using the developed technical relevance model, which follows the method of Failure Mode Effects Analysis (FMEA) and is suitable for use in small and medium enterprises (SME), who are the main performers in this industry. The method quantifies the technical severity and considers the difficulty of detectability as shortcomings occur and the probability of occurrence $[18,19]$. Although this approach is most often used for production, the method has also been relevant in the construction industry $[20,21]$. The method is not flawless and has been criticised due to the mathematical model by Puente [22] and Bowles [23]. They argued that as the occurrence and detectability factors are linear, their effect might be overrated in comparison to the technical severity. Pillay and Wang [24] improved the model with a weighting factor to balance the subjective evaluations. Researchers even included various other factors in the model to provide more specific results according to their research goals $[25,26]$.

The main aim of this research was to develop an assessment model of the shortcomings that quantify the on-site degradation factors of the ETICS using the FMEA method [27] for SMEs. To achieve this, we develop a severity weighting system according to the essential requirements set for the façade system and integrate it into a technical relevance assessment model. The results are presented by the sequence of the construction process as individual components, as well as the final output - technical risk priority number (TRPN). The developed tool enables clients, supervisors, and contractors to focus their attention on the most relevant on-site activities to increase the quality of the ETICS and their benefits. The assessment of the impact factors differentiates the high-risk activities during construction.

\section{Materials and Methods}

The developed technical relevance model evaluates the on-site degradation factors of the ETICS and is suitable for SMEs who have a limited number of experts. The research design is divided into six phases (Figure 1). The model can be followed by individual companies to calculate firm-specific risks as construction products are improving rapidly and new construction technology is constantly emerging. To start, the scope of the model and limitations were set (Step 1), followed by the selection of experts (Step 2) and development of the questionnaire (Step 3). The data collection and analysis were divided into two sets of experts' judgements due to the differences in the nature of the data. The evaluation of technical aspects requires in-depth knowledge and understanding of the façade system (Step 4). The occurrence ratio and detectability of the shortcomings is more region-, company-, 
and craftsmen-specific and concerns the forecasting as well as practical experience (Step 5). The technical risk is calculated as the converged values are established (Step 6).

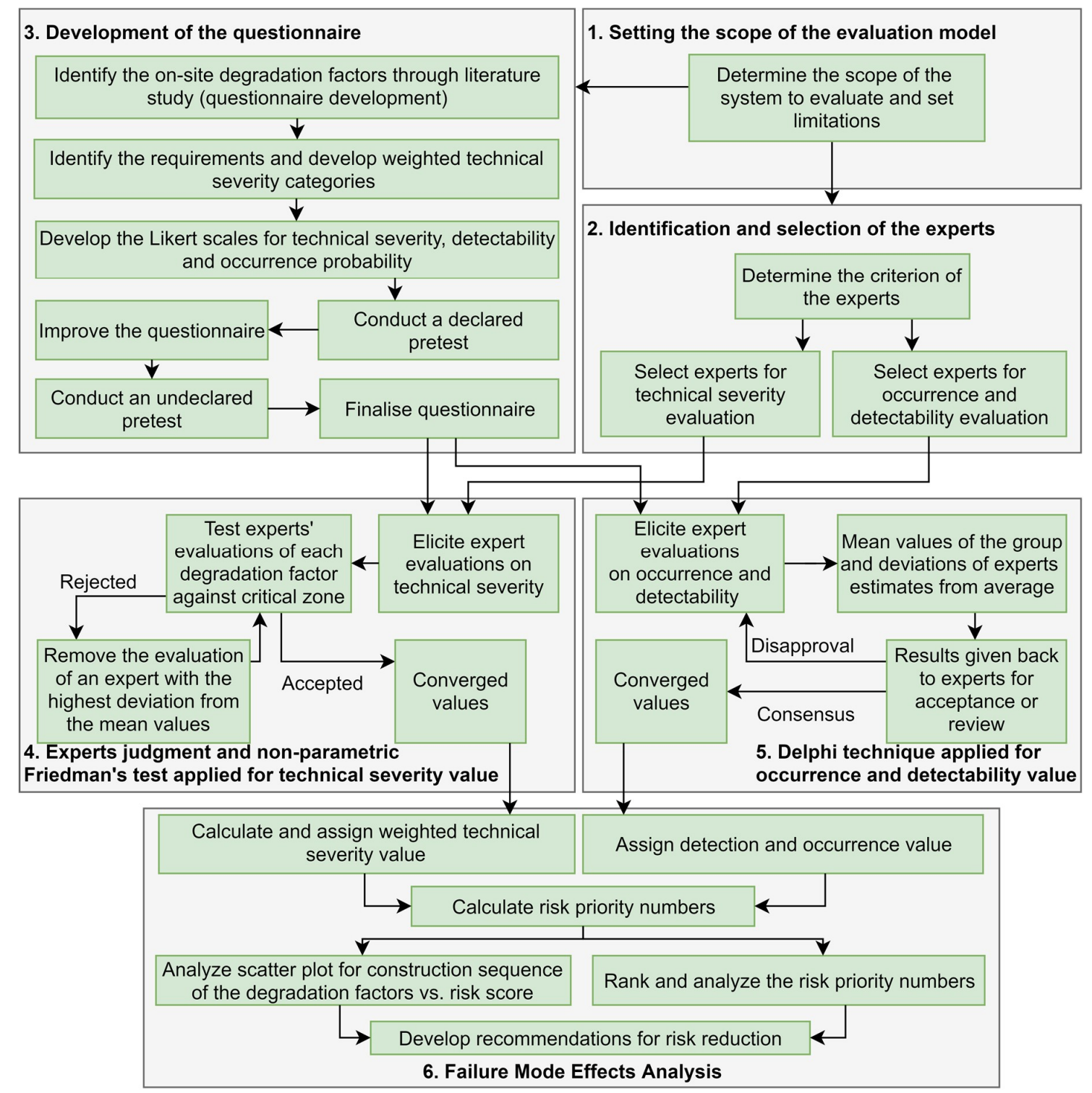

Figure 1. Research design for the technical relevance model.

\subsection{Study Scope and Limitations}

The data collected to test the simulation model concerned the ETICS with the following characteristics, which are correspondingly the limitations of data collection: the subject is an existing multi-apartment building; external walls are made out of masonry or prefabricated concrete panels; the fixing method for the ETICS is either purely bonded with adhesive or mechanically fixed with anchors and supplementary adhesive; reinforcement consists of a mixture and glass-fiber mesh; the thermal insulation product is composed of mineral wool or expanded polystyrene with a thickness of $150 \mathrm{~mm}$ to $250 \mathrm{~mm}$; and the study concerns the region-specific aspects of Estonia, which lies in the Dfb (snow climate, fully humid, warm summer) zone according to the Köppen-Geiger Map.

\subsection{Identification and Selection of Experts}

There is no quantified data available on the research subject. Hence, expert judgement was suitable for use in this study. The selection of experts considerably affects the quality of the data [28]. 
The terms for the selection of experts was their in-depth knowledge and understanding of the technical considerations of the ETICS as well as practical on-site experience. According to Olson [29], variations in reviewer backgrounds are allowed. Hallowell et al. [30] suggested that in the construction industry, expert identification could be conducted through the membership of nationally recognized committees or by participation in similar studies. The expert should meet at least four of the following requirements: (1) at least five years of professional experience in the construction industry; (2) tertiary education degree in the field of civil engineering or other related fields; (3) professional registration in the field of construction; (4) member or chair of a nationally recognized committee for the ETICS; (5) writer or editor of a book or book chapter on the topic; (6) faculty member at an accredited institution of higher learning; (7) invited to present at a conference on the topic; and (8) primary or secondary writer of at least three peer-reviewed journal articles.

As the model was developed for usage in SMEs, the number of required experts was small. The most suitable number of panelists has not been exactly determined in the literature to quantify the experts' evaluations. The size of the group depends on the availability of the experts, available resources, and research topic [31]. In other studies of the construction industry, a small number of experts was often used. Chan et al. [28] involved eight panelists to study the selection process of a procurement system in the construction industry. Chau [32] included seven experts to evaluate the estimated probability of unit costs. Six experts were identified and selected for a risk assessment of road projects [33] and five experts evaluated construction business risks [34]. Studies have included 3-144 experts in the studies of various industries [35] and 3-93 panelists in the construction industry [31]. Hallowell et al. [30] proposed a panel size between 8 and 12, whereas Rowe et al. [36] suggested including five or more experts in the panel and pointed out that there are "no clear distinctions in panel accuracy" when the panel size varies from 5 to 11 experts. Hence, for the user of the model, at least five experts should be inclued.

To test the developed technical severity evaluation model, 14 experts with the required characteristics were identified through nationally recognized ETICS committees in Estonia and Germany who agreed to participate in various phases of the study. The panel included seven experts each from Germany and Estonia. Seven of them were consultants/supervisors, two were managers/project managers in façade construction companies, and five were technical specialists from ETICS manufacturers. Two of the experts pre-tested the questionnaire and 12 out of the 14 were involved in the judgment of technical severity in 2016. The demographics of the experts participating in the technical severity evaluation are shown in Figure 2.

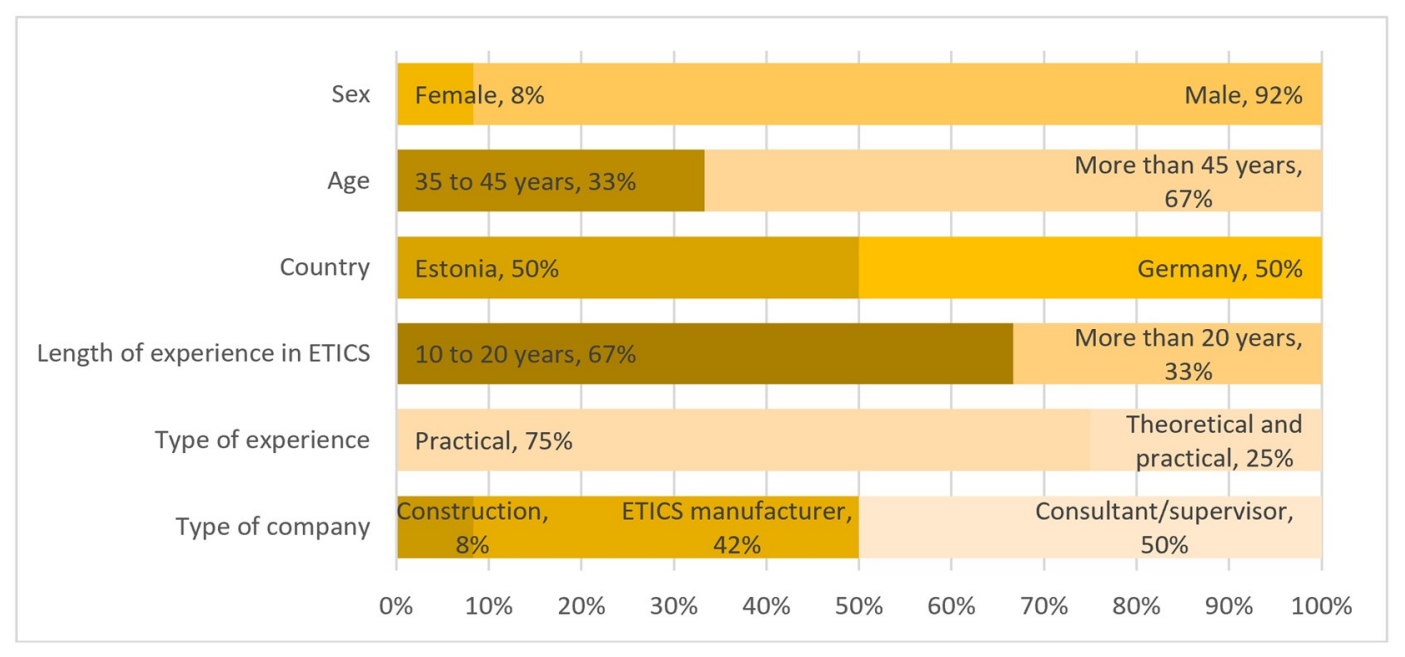

Figure 2. Demographics of the experts participating in the technical severity evaluation. ETICS = External Thermal Insulation Composite System.

As the study aimed to identify the situation in Estonia, the Estonian experts were asked to participate in the region-specific data collection. Five of the seven Estonian experts agreed to participate 
in the survey conducted in 2018. All of them had 10 to 20 years of practical experience in the field. Figure 3 visualizes the demographics. All the data were collected during face-to-face meetings due to the requirement of a high response rate. Due to the small panel size of the region-specific data collection, it can be argued that the full capacity of the Delphi technique was not fully used. As the quality of the expert panel is more significant than the size [37], and since the aim of the study was to test the developed model, the small panel size in the Delphi study was satisfactory.

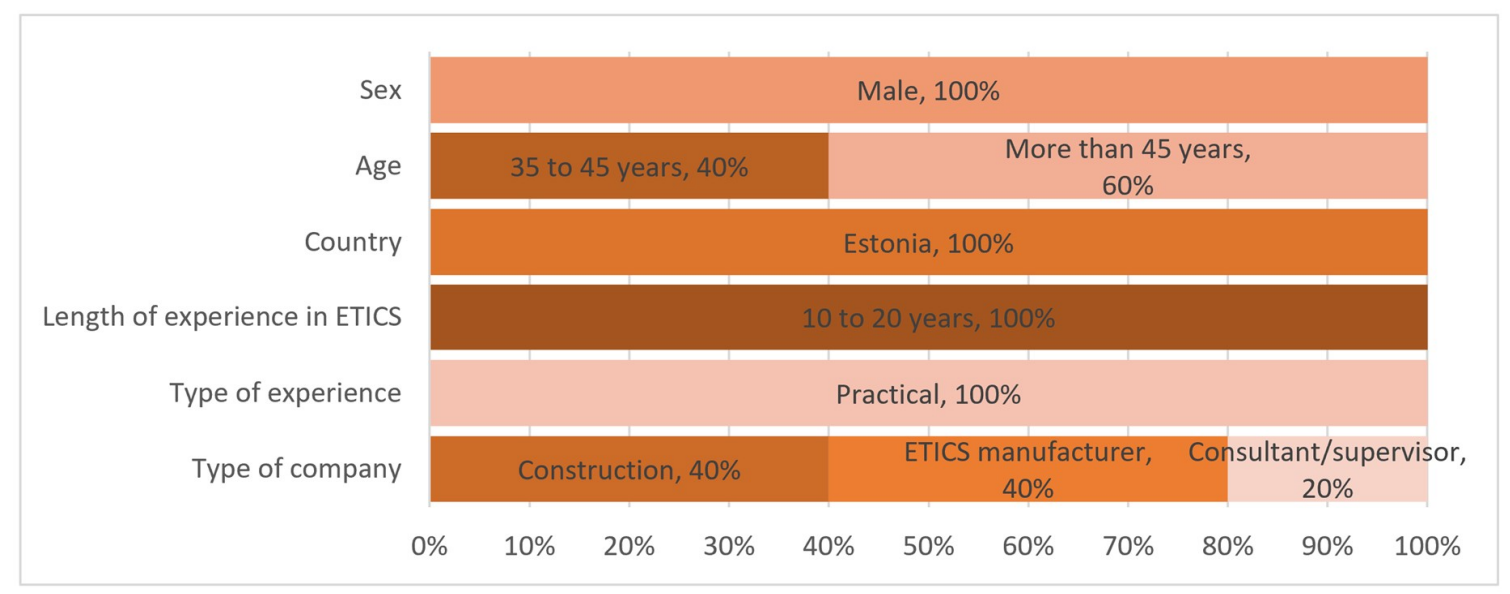

Figure 3. Demographics of the experts participating in the occurrence and detectability evaluation.

\subsection{Selection of Degradation Factors}

The list of degradation factors was collected through a literature review. The list of shortcomings is based on descriptive instructions, recommendations, harmonized standards, set requirements [38-43], studies regarding simulations or material studies made in laboratory conditions [11-14,44-67], field research $[2,3,5,7,51,68-80]$, and books on the topic $[6,9,10]$. Based on these references published between 1996 and 2015, a list of identified on-site degradation factors was created. The degradation factors were distributed according to the seven layers of the system. The construction works in the substrate layer mainly concern the preparation of the existing external wall. Adhesive, reinforcement, and finishing layers include work practices with mixtures and mesh application. Insulation and mechanical anchors specify the requirements for the insulation panels and mechanically fixed anchors. The additional details generalize the defects of the installations of auxiliary products, like windowsills and plinth areas. Table 1 shows the literature used for the selection of degradation factors and the layer to which the factor is related, whereas entire list of revealed on-site shortcomings for further evaluation is presented in Appendix A.

Table 1. Most relevant degradation factors based on the literature review.

\begin{tabular}{ll}
\hline Layer & Literature Source \\
\hline Substrate (S) & {$[6,9,10,56,64,68,73]$} \\
Adhesive (D) & {$[6,7,9-12,14,15,46,56,69,73,76]$} \\
Insulation (I) & {$[6,9,10,13,49,50,58,72,73]$} \\
Mechanical anchors (A) & {$[6,9,10,40,41]$} \\
Reinforcement (R) & {$[2,6,9,10,55]$} \\
Finishing layer (F) & {$[6,9-11,14,69]$} \\
Additional details (X) & {$[6,9,10,53,62]$} \\
\hline
\end{tabular}

To reveal questionnaire errors, one declared and one undeclared pre-test were conducted. Similarly, individual pre-testing has been used by other researchers [81] and shown good results in identifying misinterpretations [82]. The reviews were conducted individually and independently, and the results of the other evaluations were not revealed. One expert was located in Germany, 
had a doctoral degree, and had more than 20 years of experience with the ETICS as a consultant and supervisor. The second was located in Estonia, had a master's degree in civil engineering, and more than 15 years of experience as project manager in ETICS construction. Both experts were participating in the National ETICS Standards Committee. During the reviews, 11 irrelevant factors were removed from further analysis, and the wording of 16 degradation factors was rephrased to improve the legibility and suitability for systems checked.

\subsection{Technical Risk Priority Number of Degradation Factors}

The evaluation system focused on the essential technical performance requirements set for the ETICS. We assumed that if the performance of the system does not meet the desired characteristics, a failure occurs. To classify and rate the significance of each failure, the risk assessment methodology Failure Mode Effects Analysis (FMEA) was used as it enables the quantification and prioritization of risk $[20,21,83]$. The technical risk priority number of a degradation factor was calculated with:

$$
T R P N_{D F}=\overline{S V_{D F}} \times \overline{O V_{D F}} \times \overline{D V_{D F}},
$$

where $T R P N_{D F}$ is the technical risk priority number of a degradation factor, $S V_{D F}$ is technical severity value of a degradation factor, $O V_{D F}$ is occurrence value of a degradation factor, and $D V_{D F}$ is the detectability value of a degradation factor.

The simulation data were divided into technical and region-specific components. The framework of the model is visualized in Figure 4, where the occurrence and detectability are individual components, and the weighted technical severity value is a combination of eight severity categories.

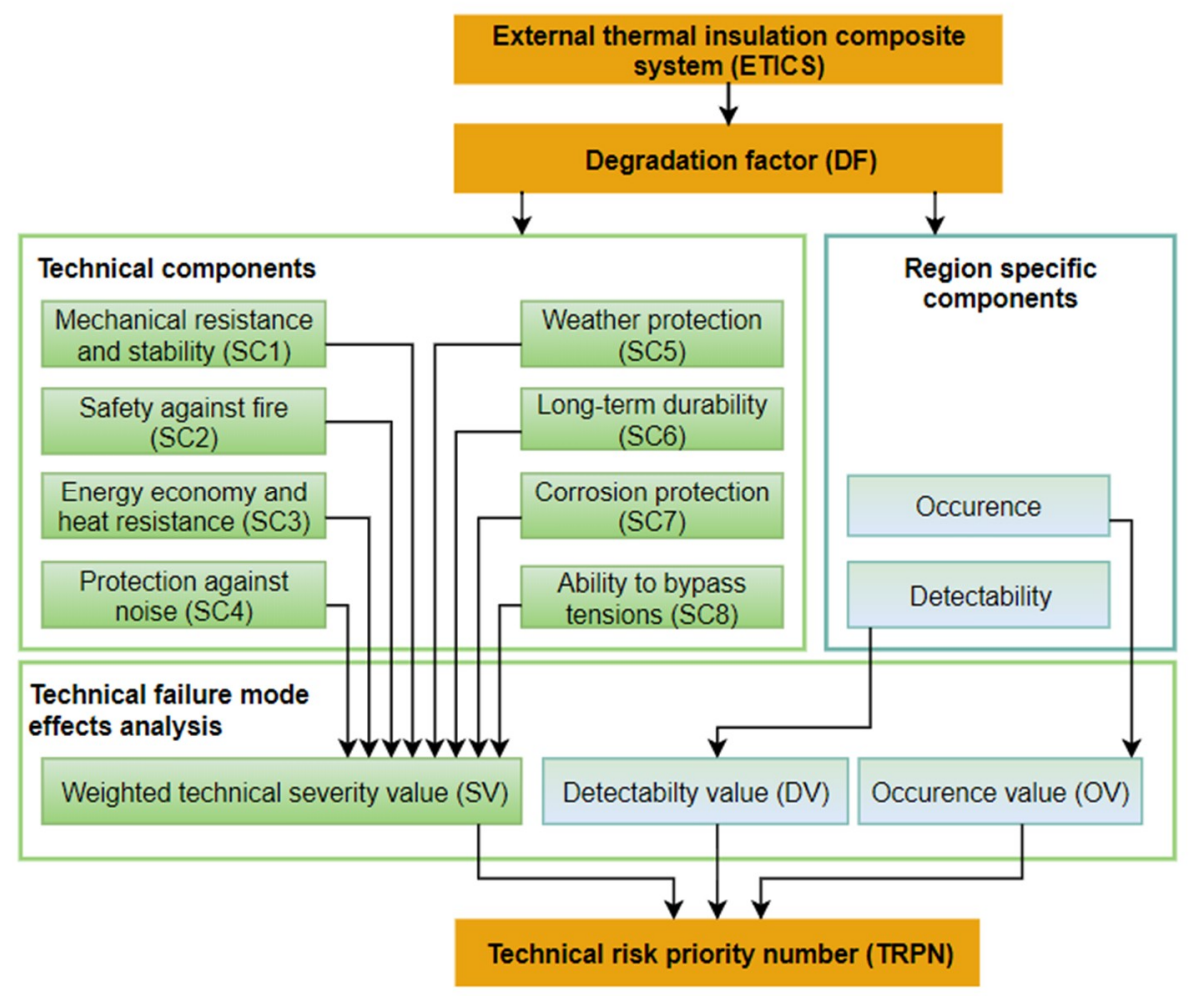

Figure 4. The framework of the technical relevance model. SC = severity category.

The experts evaluated the severity of the system's performance, the likelihood of occurrence, and detectability on a Likert scale. Likert scales from two up to 11 points have been used in other research [84]. According to Preston [84], scales below or equal to four points should be avoided. For the severity evaluation, a six-point Likert scale was used to include the value of zero, which simplifies 
the interpretation of the cases where no influence is foreseen. The detectability and occurrence were evaluated in a five-point Likert scale. The developed Likert scales are shown the following section.

\subsubsection{Technical Severity}

For the building products used in the European Union, the general international technical requirements are set by Regulation (EU) Number 305/2011 [85] (also Construction Products Regulation or CPR), which is the basis for the "Guideline for European technical approval of External Thermal Composite System (ETICS) with rendering" (also ETAG 004) [41]. The Construction Products Regulation presumes that buildings and construction products meet the performance requirements during their economically reasonable working life and describes seven essential requirements for construction products. "Mechanical resistance and stability" (SC1), "safety in case of fire" (SC2), "energy economy and heat retention" (SC3), and "protection against noise" (SC4) are considered in this study as described in the CPR. "Sustainable use of natural resources" is explained in ETAG 004 as measures on the "aspects of durability and serviceability", which concern durability from several aspects that are differentiated in this study. The system must protect against short-term weather effects like "humidity and weather protection" (SC5), deliver its functions during the whole service life ("long-term durability", SC6), and be resistant to corrosion ("corrosion protection", SC7). "Safety in use" considers the resistance to combined stresses caused by normal loads. For clarity in this research, the label "ability to bypass tensions" (SC8) is used. "Hygiene, health, and environment" considers the effect on the indoor and outdoor environment as well as pollution due to the release of dangerous substances, which is not seen as a separate severity category in this façade construction technology-related study.

Each degradation factor affects the performance of each severity category, which influences the total performance of the façade. Aurnhammer [86] estimated technical defects concerning the diminishing value to the users. In the case of a shortcoming in any segment, the final resulting value decreases. The degradation severity was evaluated with a weighted impact method, in which all categories totaled $100 \%$, describing the total failure in each category. Based on the weighting method developed by Aurnhammer [86], the adjusted distribution (Figure 5) provides an evaluation model to calculate the weighted technical severity value.

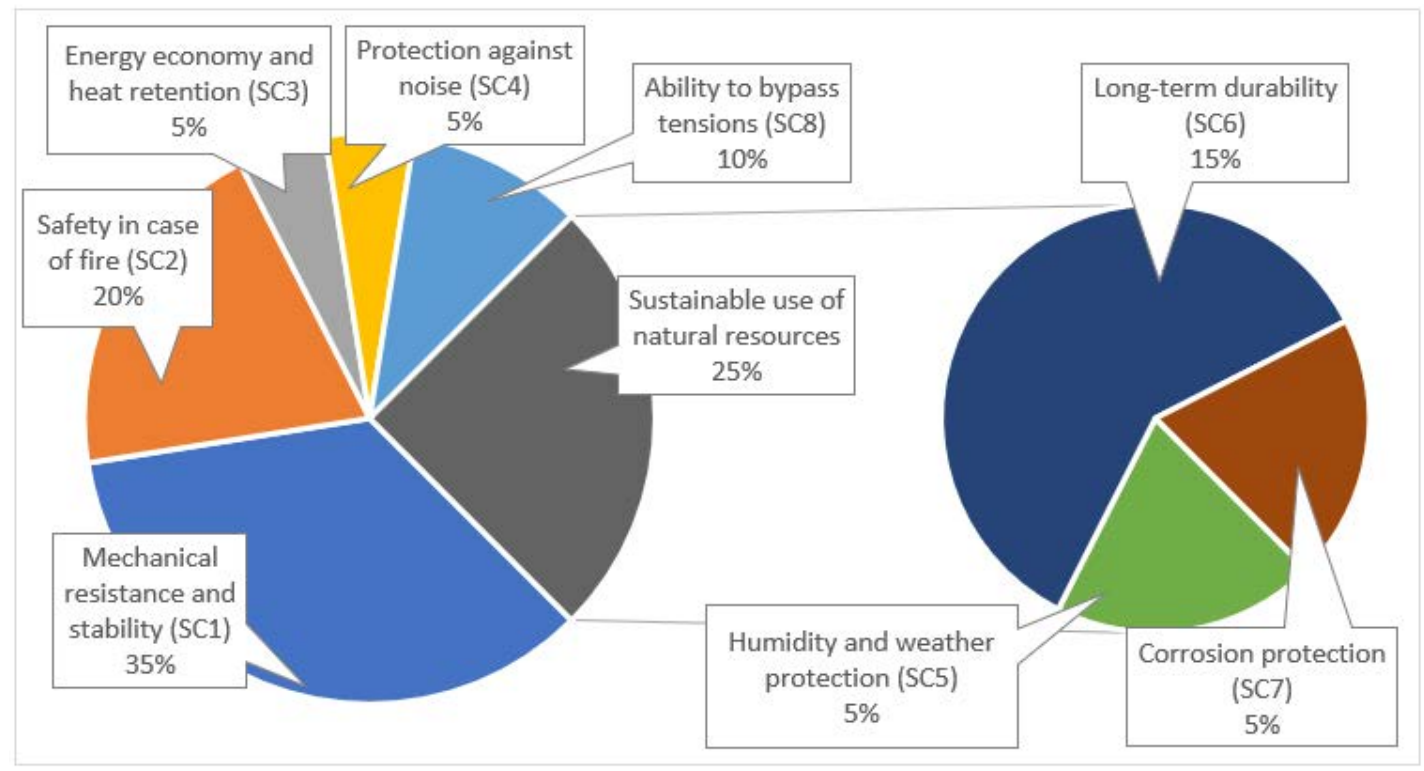

Figure 5. The weight distribution of the severity categories. 
The weighted technical severity value for each expert is calculated with Equation (2). The mean severity value of all experts is the input value for the technical risk priority number calculation in Equation (1).

$$
S V_{D F, e}=\sum\left(\frac{S R_{D F, S C, e}}{S R_{S C, \max }} \times T_{S C}\right)
$$

where $S V_{D F, e}$ is the weighted severity value of an expert, $S R_{D F, S C, e}$ is the individual rating of an expert for a severity category, $S R_{S C, \max }$ is the maximum rating value for the severity category, and $T_{S C}$ is the weight of the severity category according to Figure 5.

The developed Likert scale for the technical severity rating is shown in Table 2. The highest rating was assigned if the failure has a very high effect on the requirement and a score of zero was given when the failure has no impact on the requirement. These expert ratings were the input data for the calculation of weighted technical severity value.

Table 2. Likert scale for the evaluation of technical severity.

\begin{tabular}{llc}
\hline Risk Level & Characteristic & Severity Rating \\
\hline Very high & Total failure of the requirement & 5 \\
High & Requirement is highly influenced & 4 \\
Moderate & Requirement is moderately influenced & 3 \\
Low & Requirement is slightly influenced & 2 \\
Very low & Requirement is minimally influenced & 1 \\
No effect & No effect on the requirement & 0 \\
\hline
\end{tabular}

The validity of the severity values based on expert judgement was tested with the non-parametric Friedman's test, which increases the credibility of quantification of subjective evaluations $[87,88]$. The non-parametric Friedman's test assesses the difference between a number of related samples. The test is used as an alternative for analysis of variances for repeated measures when the same parameters have been measured on the same subjects, but under different conditions [88]. Friedman's test was used for each degradation factor separately to detect expert values that are in the critical zone. The 103 degradation factors included 991 individual evaluations; 53 degradation factors received positive Friedman's test results with the first analysis, 82 individual evaluations were in the critical zone and a maximum of four rounds were applied. After the Friedman's test, the data sets included four to 12 experimental units. As there were enough different components in the calculation, the inaccuracy of the evaluations did not have a major impact on the final results.

\subsubsection{Occurrence and Detectability Value}

The probability of occurrence rates the incident frequency during the construction process. It is a subjective evaluation by the expert and is dependent on personal experience. The pre-test questionnaire revealed that it is impossible to quantify the occurrences in a specific range and quantification of subjective evaluation was required. The rating scale is shown in Table 3. The highest value was given to often-occurring failures and the lowest value to unlikely failures.

Table 3. Likert scale for the evaluation of occurrence probability.

\begin{tabular}{llc}
\hline Risk Level & Characteristic & Occurrence Value \\
\hline Very high & Failure is almost certain & 5 \\
High & Often repeated failures & 4 \\
Moderate & Occasional failures & 3 \\
Low & Relatively few failures & 2 \\
Very low & Failure is unlikely & 1 \\
\hline
\end{tabular}


The detectability and occurrence evaluations were classified into five categories. The detectability value rates the difficulty level of on-site detection of the shortcoming. The characteristics are shown in Table 4.

Table 4. Likert scale for the evaluation of detectability.

\begin{tabular}{llc}
\hline Risk Level & Characteristic & Detectability Value \\
\hline Very high & $\begin{array}{l}\text { A potential cause of failure cannot be detected visually. } \\
\text { Additional tests need to be used. High experience required. }\end{array}$ & 5 \\
\hline High & In between very high and moderate conditions. & 4 \\
\hline Moderate & $\begin{array}{l}\text { A potential failure can be detected visually before completion of } \\
\text { the layer, during the application process or through markings on } \\
\text { the material packages. Mediocre experience required. }\end{array}$ & 3 \\
\hline Low & In between very low and moderate conditions. & 2 \\
\hline Very low & $\begin{array}{l}\text { Cause of failure can be detected after completion of the layer } \\
\text { with the less experienced observer. }\end{array}$ & 1 \\
\hline
\end{tabular}

The data collection to determine the detectability and occurrence values was developed using the Delphi technique, where independent and anonymous expert judgements are combined through mathematical aggregation [35]. The expected outcome was a consensus between the experts. The Delphi technique should be used if there is no quantifiable data available [89]. The technique requires the circulation of a questionnaire amongst the selected experts. There is no specific guideline to determine when a consensus has been achieved. In this study, the consensus was achieved when the experts agreed upon the mean values of the group.

The experts were asked individually and anonymously to provide their evaluations. According to the questionnaire, each expert needed to provide evaluations for occurrence and detectability. To obtain a high response rate, a meeting time with each expert was individually organized. During the face-to-face meeting, the questionnaire was completed by the expert. The responses from all experts were summarized and mean values were calculated. The collective mean results were sent to each expert and they were asked to revise their evaluation or agree/disagree with the collective result. During the next two weeks, three participants agreed with the collective results. Two experts reviewed the group results after a reminding phone call and stated their agreement with consensus. Hallowell et al. [30] described the "bandwagon effect", where decision makers may feel pressure to confirm the opinion of a group. Due to the fast agreement with the consensus and to investigate whether this described effect was present, the team of experts was brought physically together. The highest and lowest evaluations were discussed with the group to check if there were hidden assumptions. Positively, the consensus did not change after the meeting. The primary reason was that the individual evaluations depend highly on the skills and experience of the expert and the results may vary. The data collection process was conducted in 2018.

\section{Results}

The objective of this study was to prioritize on-site construction process activities to enable better resource allocation to quality control during construction. The developed technical severity model combines the effect of weighted technical severity, the probability of occurrence, and the detectability of the on-site construction work. The output values were divided into layers of the applied system and ETICS types for analysis. ETICS 1 concerns the purely bonded system with polystyrene. Polystyrene with mechanically fixed anchors and supplementary adhesive describe ETICS 2. ETICS 3 represents the mineral wool system with the same fixation type as ETICS 2 . The benefit of the differentiation by ETICS type is to provide the ability to assign only relevant degradation factors to the simulation under evaluation. The differentiation by layers of the system allows the comparison between the sequences of the construction process. 


\subsection{Weighted Technical Severity Value}

The primary variable for TRPN calculation is the average weighted technical severity value, which considers the technical significance of the degradation factors in the eight severity categories. The distribution of the average severity values by layers is shown in Figure 6, where higher values denote higher significance. The degradation factors in the substrate and adhesive layers have significantly different severity values when ETICS types are compared. ETICS 1 is highly dependent on the characteristics of adhesion and has a higher severity value, whereas ETICS 2 and 3 share the fixation risk with mechanical anchors and have lower values. In other layers, the ETICS types have comparable values.

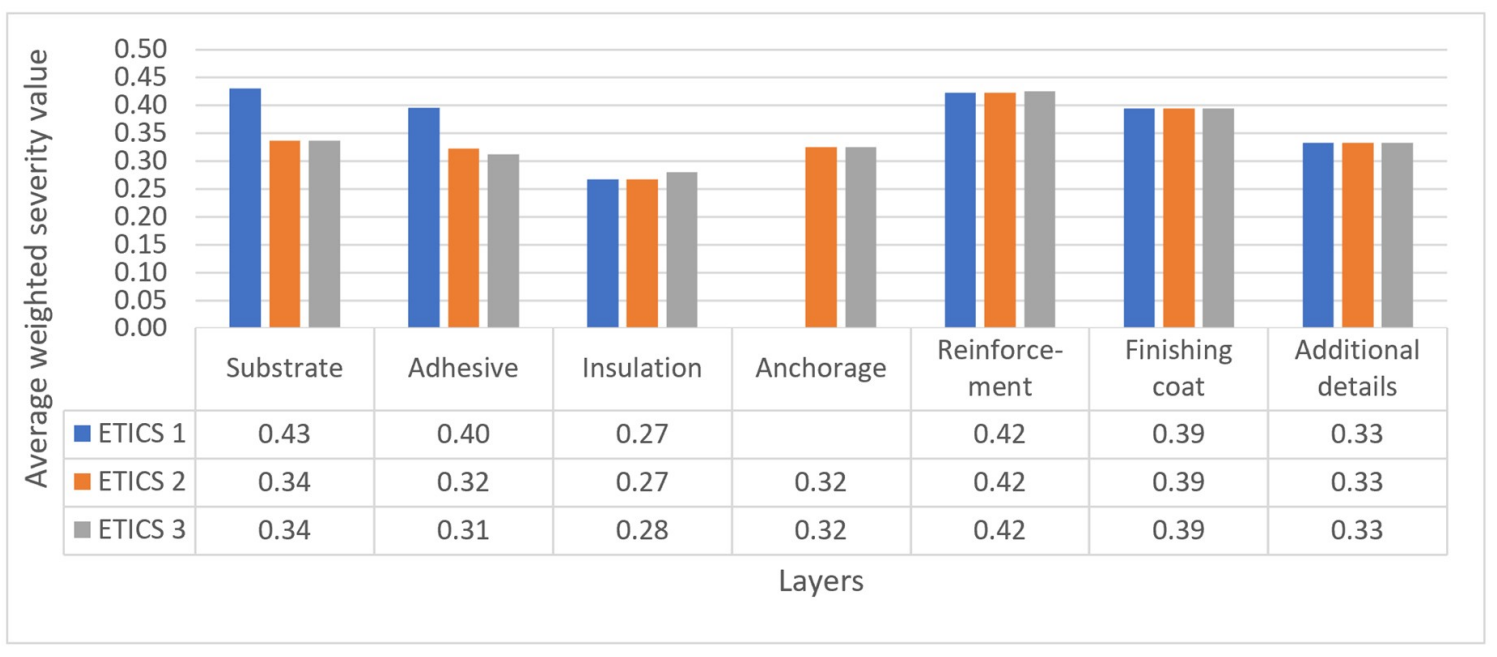

Figure 6. The average severity value by the layer of the system.

The severity values (SVs) of the degradation factors were placed in the order of the construction, shown in Figure 7. The colored horizontal lines visualize the average values of the weighted technical relevance for each ETICS type by layer. The standard deviations were the smallest in the substrate (0.04 to 0.06$)$ and adhesive ( 0.07 to 0.08$)$ layers. The colored areas represent the range of a specific layer. The groups of degradation factors discussed more specifically are identified with green lines.

The SV1 group includes the degradation factors of the purely bonded system in the substrate layer, which involves preparation of the surface. Substrate coverage with oil (S1b), dust (S2b), biological growth (S3b), old paint (S4b), as well as decreased load bearing capacity (S5b), have high technical severity.

The second highly relevant group was SV2, which describes missing adhesive on the edges of insulation (D1b), freezing of the mixture (M9b), exceeded working time of the adhesive (D7b), and adding unsuitable ingredients (M8). The high technical severity of the substrate and adhesive layers is caused by the construction activities that are responsible for the fixation of the system to the existing external shell of the building. The degradation factors in the substrate layer include the pre-treatment of the surface and the properties of the substrate that affect the characteristics of adhesion. The existing exterior wall of the building must resist the additional load caused by the ETICS and is responsible, to a large extent, for the stability and adhesion characteristics of the attached system, whether the fixation relies on mechanical anchors or adhesive. The factors in the substrate and adhesive layers have a relatively high impact on the mechanical stability of the system and mediocre influence on long-term durability. 


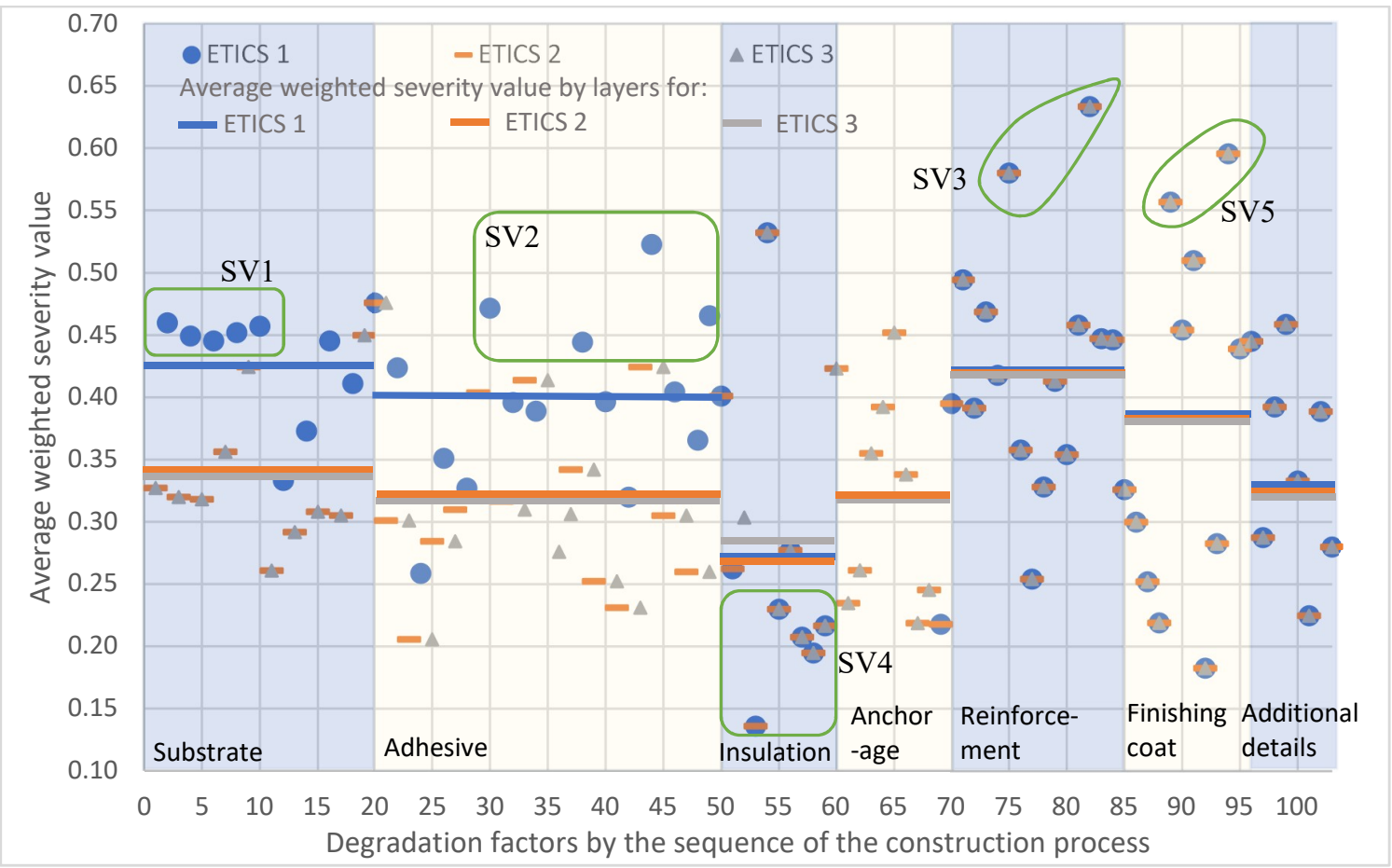

Figure 7. Severity value of the degradation factors based on the steps of the construction process.

The highest technical impact was caused by the shortcomings in the reinforcement layer, which is responsible for the essential task of stress transmission within the system. In a correctly applied layer, the stresses are transmitted to the mesh applied. These factors considerably impact mechanical stability, but also the ability to bypass tensions, long-term durability, and weather protection. The relatively high impact of these severity categories can be explained by the requirement to bear stresses caused by the external environment, like hygrothermal changes during different seasons and freeze-thaw cycles. The two degradation factors with high severity were in the SV3 group: a thin layer of reinforcement mixture (R6) and the freezing of the reinforcement mixture (M9c).

Similar to the adhesive layer, mechanical anchors fix the system to the existing external shell and bear wind suction loads. Their technical effect mainly concerns the mechanical stability of the system, whereas all other severity categories remained rather irrelevant.

The degradation factors in the additional details layer were technically as relevant. In this study, the layer includes more generally described shortcomings that reflect the installation of additional products in contact with the system (i.e., application of windowsills, fixations that require penetration through the system, and installation of roof edge details). The additional details have high ratings on the severity categories of energy efficiency, and, to some extent, protection against noise, weather protection, long-term durability, and corrosion protection. In comparison to the internal layers of the system, the shortcomings in this layer mostly affect the moisture-induced problems as sealants fail and enable the external moisture to penetrate the system.

An unexpectedly high severity value was assigned to the finishing coat and the degradation factors in group SV5. The external layer, in addition to its aesthetic function, is responsible for weather protection to some extent, although the ETICS is designed to function without the finishing layer. The natural conditions include a combination of effects from which the external layer provides protection: wind, rain, pollutants, relative humidity, temperature, and solar radiation. The results show a higher influence on the severity categories that consider the external effects: weather protection, long-term durability, and ability to bypass tensions. The shortcomings in the finishing layer had the highest standard deviation of 0.15 . The degradation factors with high severity value include the risks of the mixture: freezing of the mixture (M9d), unsuitable storage conditions (M1d), and increased 
amount of kneading water (M3d). The lesser risks concern the adhesion with the previous layer, including missing primer (F1) and a not cured reinforcement layer (F2).

The insulation layer received the lowest average technical severity value. Although the primary function of the insulation is to reduce thermal conductivity, defects also affect noise protection, and all other shortcomings have extremely low influence (group SV4). The broken insulation plates (I9) and airflow on the surface of the substrate (I4) have an increased effect on noise protection, as well as on safety in case of fire. To some extent, the shortcomings influence the ability of corrosion protection due to moisture-induced problems in the system. Otherwise, the shortcomings regarding the application of the insulation layer have minimal influence.

\subsection{Technical Severity Ratings}

The comparison of unweighted severity ratings of singular severity categories to each other (Figure 8) showed that the severity categories of mechanical resistance and stability, and long-term durability were affected the most. The standard deviations were 1.02 and 0.81 , respectively. The upper quartile of the mechanical resistance and stability category included nine degradation factors, which emphasizes the relevance of freezing of mixtures (M9c, M9b, and M9d) and the substrate (S10a and S10b), unsuitable mixture storage conditions (M1b, M1c, and M1d), unprepared substrate surface (S1b, S2b, and S4b), and usage of unsuitable anchor type (A9). The long-term durability category induced three factors: freezing of reinforcement (M9c) and finishing mixtures (M9d) and a high share of kneading water of the finishing layer (M3d).

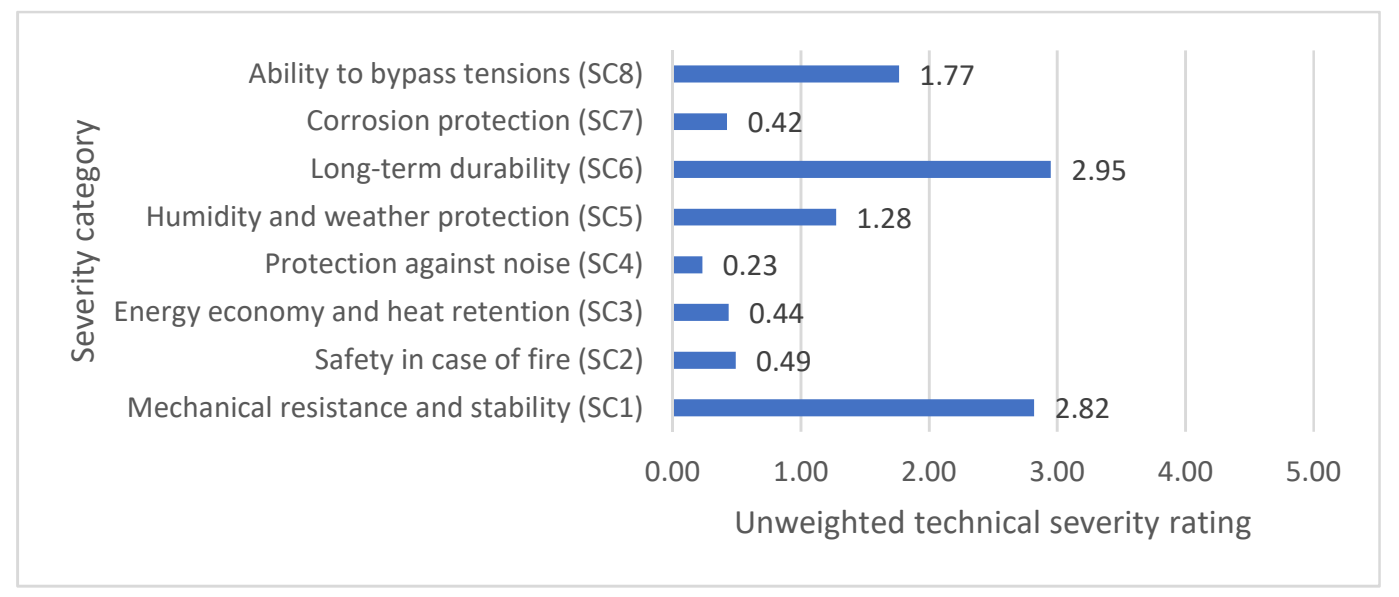

Figure 8. Average unweighted technical severity ratings by severity category.

The correlation analysis of the severity categories revealed high correlations within the groups of high-ranking severity categories (SC1, SC5, SC6, and SC8) and within low-ranking categories (SC2, SC3, SC4, and SC7). The regression analysis of the low-ranking categories included many variables that received a low score, as they have no impact, which enabled the interpretation of the correlation analysis results as irrelevant. The regression analysis in the high-ranking group had a highly positive $R^{2}$ value (0.60) for the pair of long-term durability and ability to bypass tensions (Figure 9a). The results showed $60 \%$ of the degradation factors that affect the ability to bypass tensions also increase the value for humidity and weather protection. A similar result was obtained from the linear regression analysis for the pair of weather protection and long term-durability (Figure 9b), which had an $R^{2}$ value of 0.38 . The failure in the category of weather protection also reduced the long-term durability of the system. The other three pairs (SC1 and SC8, SC1 and SC6, and SC5 and SC8) had $R^{2}$ values between 0.28 and 0.29 , providing a modest explanation of the model. We interpreted this as meaning that the defects that cause a decrease in mechanical stability also decrease the long-term durability and the ability to bypass tensions. Weather protection decreases through the defects in the ability to bypass tensions. 


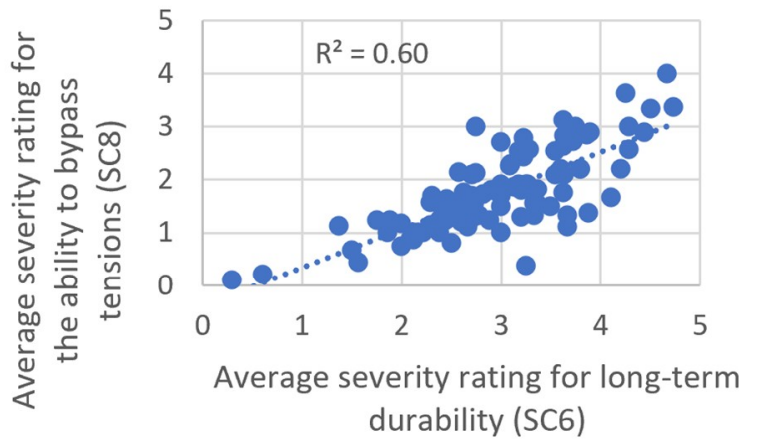

(a)

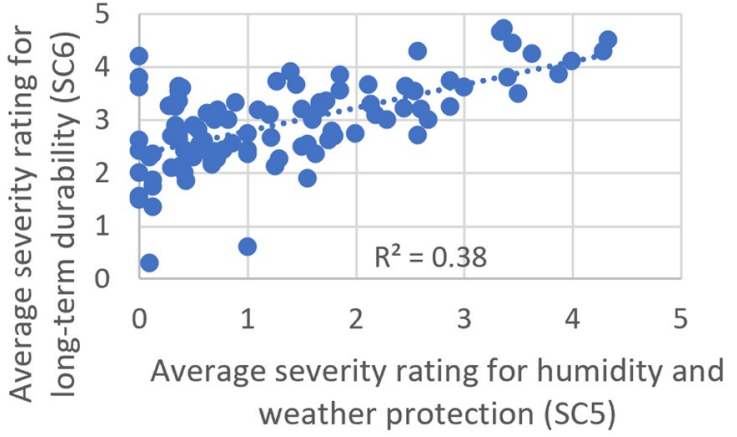

(b)

Figure 9. (a) Linear regression for long-term durability (SC6) and ability to bypass tensions (SC8), and (b) humidity and weather protection (SC5) and long-term durability (SC6).

\subsection{Probability Value}

The second relevant component to the prioritization of the shortcomings is the probability of occurrence, as it rates the frequency of an incident during the construction process. The higher value emphasizes the shortcomings that occur more often. The average values of the likelihood of the occurrence in the seven layers ranged from 1.43 to 2.80 out of 5.0, as shown in Figure 10.

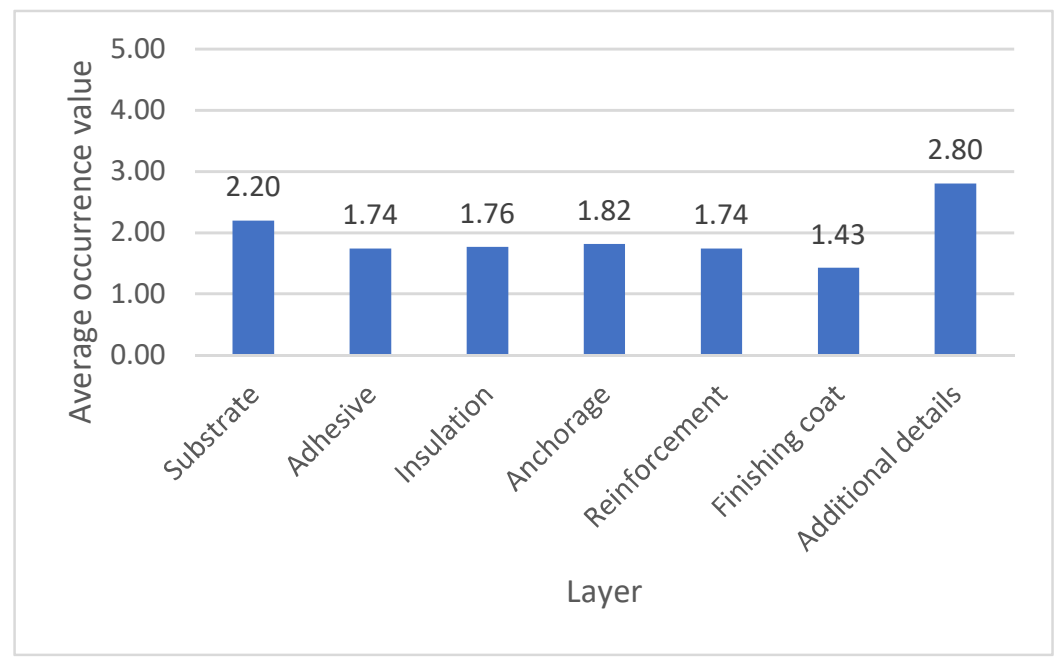

Figure 10. Average occurrence value by layers.

The average occurrence values of the degradation factors were placed in the order of the construction process in Figure 11. The average values by layer are shown with colored lines. The comparison between the three ETICS showed no significant effect, and the difference is not shown separately. 


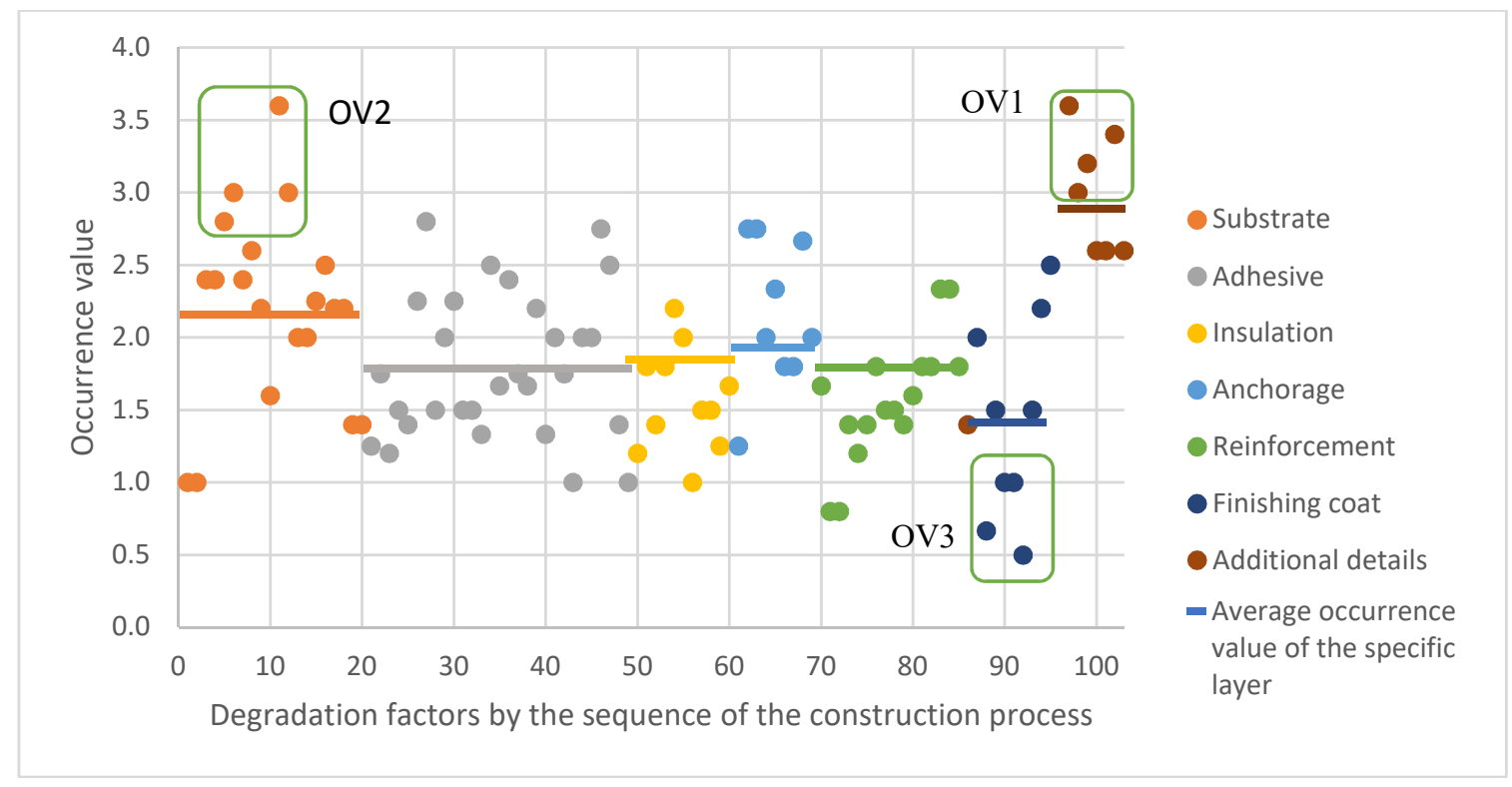

Figure 11. Occurrence value (OV) of the degradation factors placed in order of the construction process.

The degradation factors including the additional details received the highest average rating (2.80), followed by the substrate layer (2.12). The shortcomings in the additional details layer are described in a more general manner and therefore include an increased variety of risks, which probably increase the occurrence rate in comparison to other layers to some extent, which are more specifically described. In the OV1 group, the highest occurrence values included problematic structural expansion joints (X1) and penetrations through the system due to fixation (X7).

The substrate layer included activities that are often intentionally not conducted, and they do not cause a visible problem unless other failures occur (OV2 group). Such degradation factors included cleaning of the surface from biological growth (S3a, S3b) and levelling the surface (S6a, S7b). An increased amount of adhesive is sufficient to decrease the risk. A slightly lower occurrence value was detected for the finishing layer (1.43), pointed out in the OV3 group.

\subsection{Detectability Value}

The third component of the TRPN calculation is the detectability of degradation factors during construction. The average detectability value ranged from 1.20 to 2.82, as shown in Figure 12, where higher values indicate increased risk and lower detectability.

The degradation factors with the highest detectability values were in the adhesive layer, as this layer is covered immediately with the insulation plate, making it impossible to detect shortcomings after application without a destructive test. The second highest rating was for the reinforcement layer, where the mesh is covered during the application. The detectability remained slightly better, as the surface stays open and visible defects can be detected. The layers that are accessible for quality control for a longer period had lower detectability values. These layers included mechanical anchors, insulation, additional details, and the finishing layer. 


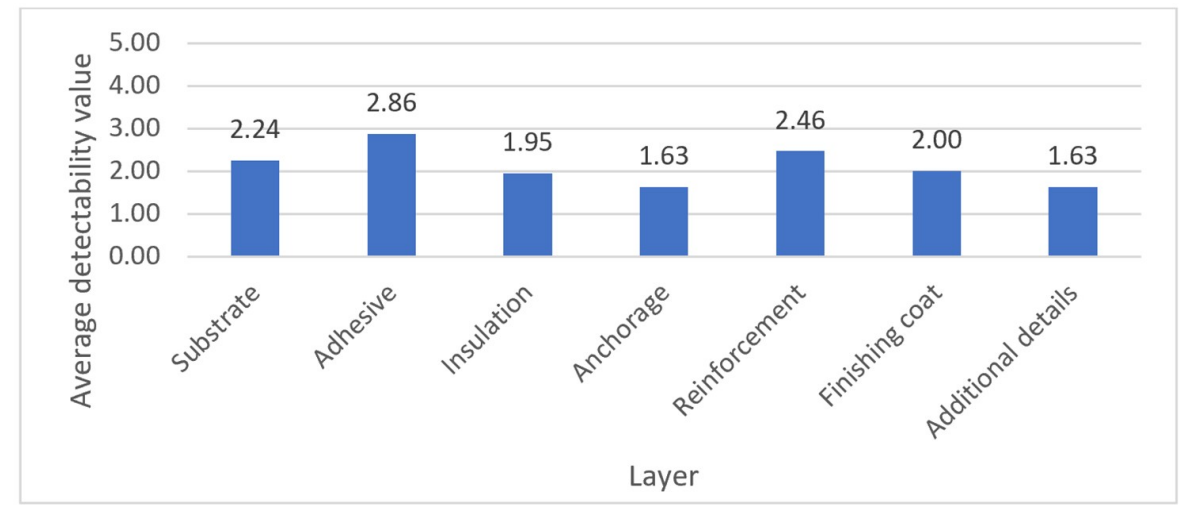

Figure 12. Average detectability value by layer.

The detectability values of the degradation factors are visualized in the order of the construction process in Figure 13, where the average values are shown with colored lines. The shortcomings in the substrate layer are visible for quality control for a longer period. However, the defects are often hard to detect and require additional measures to be taken in some cases (DV1 group), which is the reason for the high standard deviation (0.76). These degradation factors included the low load-bearing capacity (S5b, S5a), unsuitable type of adhesive (S7a, S7b), and chemical reaction between the remaining paint and applied adhesive (S4a, S4b). Additional measures should be taken to check the adhesion properties of the external surface and to test the pull-through strength of the structure. The variance between the different ETICS was very low.

The insulation layer had a high standard deviation (0.92) due to the DV2 group that had a low detectability value, and the DV3 group that had a high value. High detectability values in the DV3 group included two shortcomings: continuous gaps between the insulation layer and substrate (I4) and unfinished diffusion process of the polystyrene insulation plates (I2). On average, the mechanical anchors had good detectability (group DV5), except for the three factors in group DV4: cleaning of the anchor hole (A10), application of unsuitable anchor type (A9), and increased diameter of drilled anchor hole (A1).

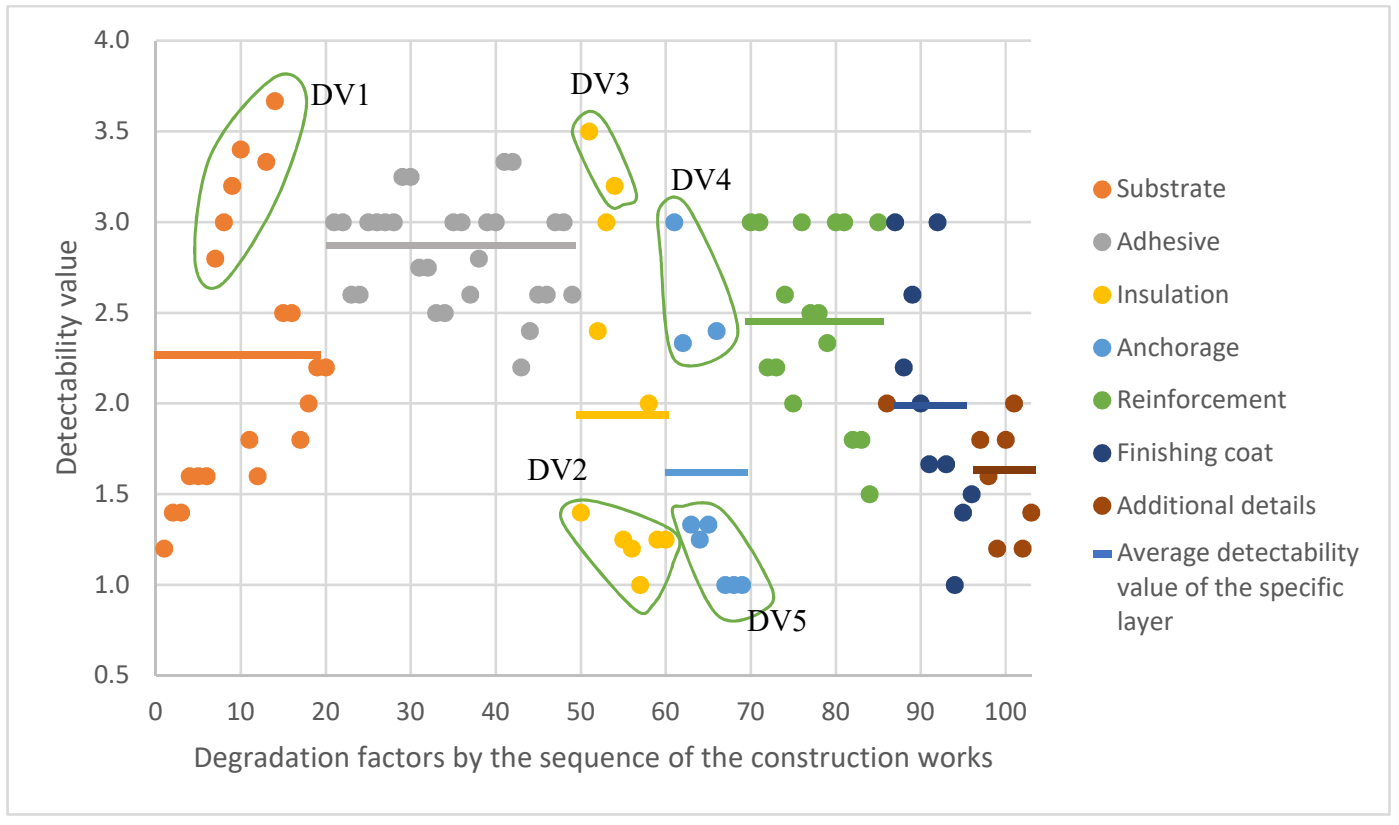

Figure 13. Detectability value (DV) of the degradation factors by the sequence of the construction process. 


\subsection{Technical Relevance According to the Risk Priority Number}

The technical risk priority number (TRPN) is a combination of the weighted technical severity value, the detectability value, and the occurrence value. The results by layer and ETICS type are shown in Figure 14, whereas Figure 15 positions the degradation factors according to the TRPN in the order of the construction process.

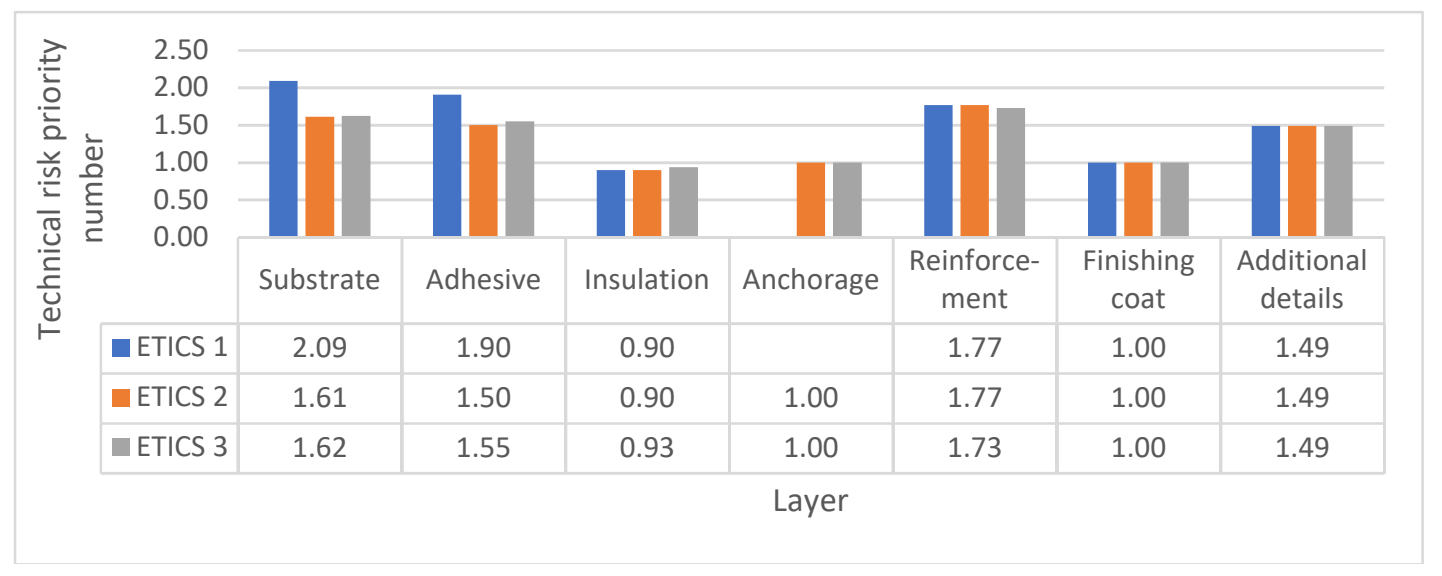

Figure 14. Average value of technical risk priority number by layer and ETICS type.

The correlation and regression analysis between the pairs of severity value and occurrence value, and severity value and detectability value, showed no relevant correlation. Between the variables of occurrence value and detectability value, there is a weak negative correlation $(r=-0.24)$, though the $R^{2}$ in the linear regression was 0.059 , which does not explain the relationship between the variables. In comparison to the average weighted severity values shown in Figure 7, the reinforcement, substrate, and adhesive layers retained their high average relevance rating. The deviation in all layers was relatively high. In the substrate and adhesive layers, ETICS 1 increased TRPN values due to the differences in severity values between the systems. Occurrence and detectability values had no significant difference in comparison to the ETICS types observed.

The highly relevant degradation factors in the substrate layer are shown in the technical risk (TR)1 group (Figure 15). The incidence when the substrate is covered with chemically reacting remaining paint (S4b), usage of unsuitable adhesive type (S7b), and low humidity of the substrate as inorganic adhesion is applied (S8b) are highly relevant for ETICS 1. The systems with mechanical anchors and supplementary adhesive (ETICS 2 and ETICS 3) were highly influenced by the low load-bearing capacity of the substrate (S5a). In the low relevance group TR2 (substrate covered with oil; S1a, S1b), the relevance decreased due to very low values of occurrence and detectability.

The adhesive layer had the most relevant shortcomings in the TR3 group. Insufficient adhesive (S3a, S3b) received very high occurrence and detectability values, increasing its relevance. Three degradation factors with relatively high detectability values also belong to this group: dry curing conditions (M11b), lack of pressure during application of insulation plates (D8b), and adhesive not rubbed into mineral wool insulation plate (D4a). The low relevance group TR4 included the mixture-related factors that reduced their relevance due to their low occurrence value. The factors include only the mixture preparation process: wrong material storage conditions (M1a, M2b), clots remain in the mixture during mixing process (M2a, $\mathrm{M} 2 \mathrm{~b}$ ), and high share of kneading water (M3a).

The insulation layer and mechanical anchors included the majority of the degradation factors in the low relevance group TR6. Although the occurrence value of the shortcomings for mechanical anchors was relatively high (Figure 11), the good detectability and below average technical severity reduced the TRPN relevance. However, there were three degradation factors with a high TRPN in the TR5 group. Although continuous gaps that enable an internal airflow (S4) had high relevance in all three components, increased diameter of drilled anchor hole (A1) and unsuitable anchor type (A9) had 
increased relevance due to difficult detectability. The detection is more problematic in this layer as the quality check must occur during the application process.

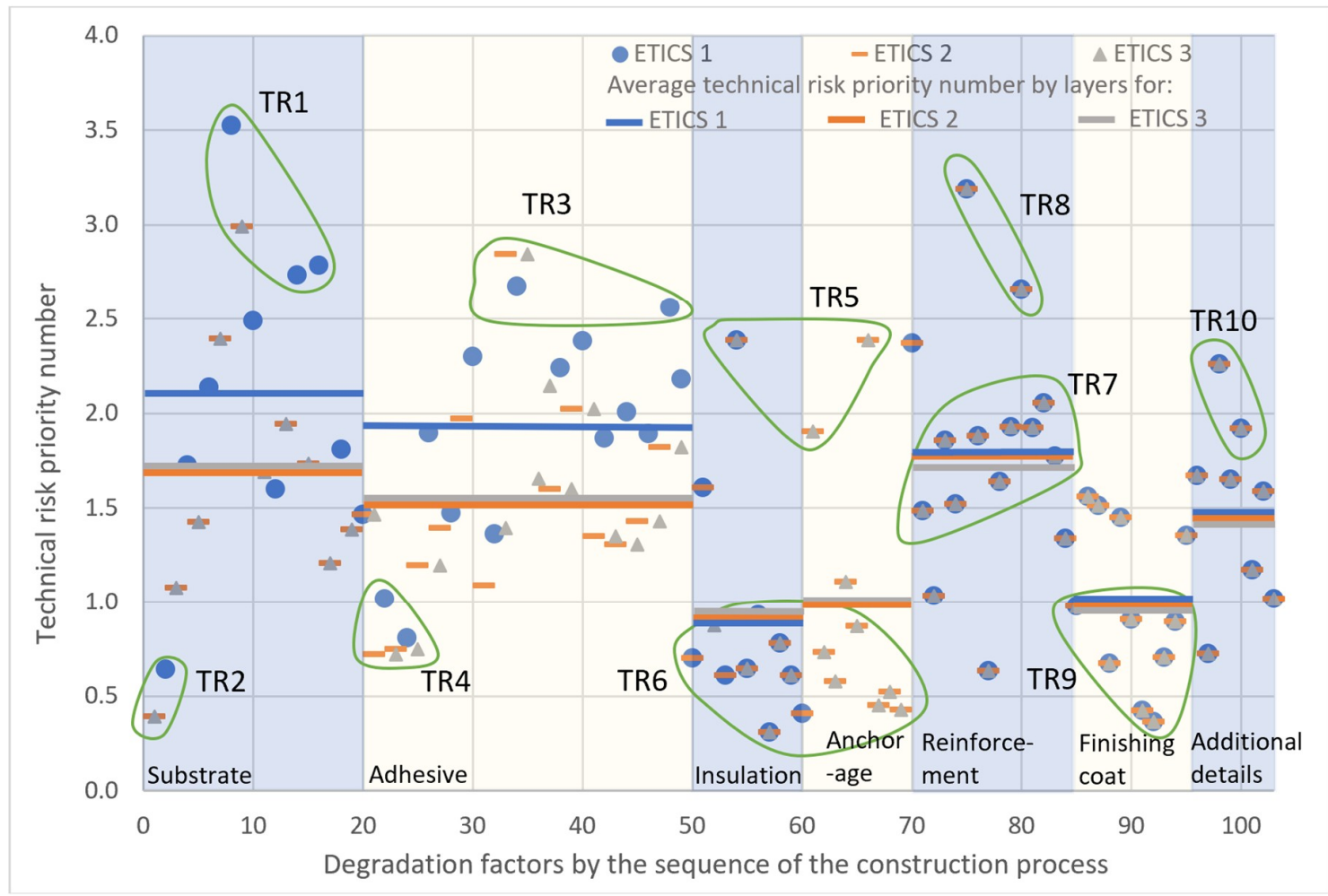

Figure 15. Technical risk (TR) priority number of the degradation factors in order of the construction process.

The reinforcement layer had the highest average TRPN and the majority of the degradation factors were positioned near the average value (the TR7 group). The degradation factors of the thin reinforcement layer (R6) and layers not applied in wet to wet condition (R7) in the TR8 group reduced the ability to bypass tensions into the mesh and were the most relevant. Thin reinforcement layer (R6) had, in comparison, a higher severity value due to the impact on the long-term durability but is easier to detect as the pattern of the mesh is visible after completion of the layer. Layers not applied in wet to wet condition (R7) can be detected only during the application process.

The risks in the finishing layer, mostly assembled in the TR9 group, decreased its relevance due to the low occurrence value. The layer has no degradation factors that are considered highly relevant to the system's performance.

The shortcomings in the additional details layer decreased the relevance due to their low detectability value but remained relatively high as the failures occur rather often. Most problematic was moisture penetration into the system due to problematic solution windowsills (X2) and other fixed frame connections (X4) in the TR10 group.

\section{Discussion}

This section reviews the research method from two aspects and discusses future applications.

The FMEA method was initially developed in the 1950s as a military procedure in the USA, and since then, critics have pointed out the flaws. The FMEA method has been used in the construction industry in several studies $[20,21,83]$. Layzell [83] applied the method to a similar cladding system and stated that the application and the results of the method depend on the availability of the data. The data in this research involved quantifying the subjective evaluations of the experts. If more quantifiable observations are made for any of the components (severity, occurrence, or detectability), the data could be more specific. However, comparative relevance is not expected to differ significantly. At this moment, 
there are no more specific quantified data available. Nevertheless, the outcomes of the single parameters as well as the TRPN results were logical. Additional degradation factors should be integrated into the model and evaluated as technical aspects of ETICS or its application process alter.

Secondly, the results of the model are a product of three variables: severity, occurrence, and detectability. Puente [22], Bowles [23], and Wang [24] argued that simple multiplication of ordinal scales might be misleading, as different combinations might produce the same output value. There are also concerns about the interpretation of the results of this research. The outcomes of detectability and occurrence are the result of subjective expert judgement. The change in one variable has a relatively large impact on the risk, upon which the final recommendations were based. In the earlier work of Bowles [90], a disadvantage was detected in the occasion when multiple severity effects are occurring. To reduce the impact of this disadvantage, a weight factor of the technical severity categories was implemented, and the analysis aimed to observe the impact on the system's total performance.

The external envelope of a building is also exposed to weather effects after the completion of the application process. The materials are affected by radiation [79], pollution [3], freeze-thaw cycles [44], humidity, the direction of the façade, and changes in porosity $[45,67]$, which all impact the durability of the façade. Finnish research on the hygrothermal behavior of ETICS [60] highlighted that the high relative humidity during freeze-thaw cycles is problematic, and there is a need for increased protection against frost attack in cold climates. Therefore, we expect that in milder climate conditions, on-site shortcomings will appear in the long term. In this study, the climate condition considerations may have affected the probability of occurrence of the degradation factor. To mitigate this influence, the experts evaluated the occurrence frequency of the shortcomings observed during the construction process and this was not confused with the occurrence of visible degradation during the exploitation period.

Additionally, the latency of the shortcoming has an economic effect, as repair costs increase the size of investment and affect the decisions on quality control. The cost component is highly relevant in terms of the owner's and contractor's quality considerations. Equilibrium could be found in future research between quality increase and risk mitigation. To find the cost component of ETICS, several aspects should be considered. The economic component is project-specific and depends on the chosen system, logistics, general economic situation in the region, latency period of the shortcoming, and other aspects.

In this study, the model included three components in the mathematical aggregation. To consider the impact of climate and the cost of repair, a multiplier could be developed to calibrate the relevance. Future research could implement these considerations into a unified model.

\section{Conclusions and Recommendations}

The usage of External Thermal Insulation Composite Systems (ETICSs) is increasing in Europe as the existing dwellings are refurbished according to newly introduced energy efficiency measures. The façade system has advantages for the building and owners but requires additional quality control to reduce the degradation caused by often-occurring minor shortcomings during the construction process.

We developed a technical severity evaluation model to quantify the relevance of on-site shortcomings of ETICS. The model followed the Failure Mode Effects Analysis method and considered the technical severity, and the probability of occurrence and detectability of deviations. The data were collected from experts' judgement and validated with the non-parametric Friedman's test and the Delphi technique. The impact of the selected 103 degradation factors were quantified and presented in the order of the construction process. The technical relevance assessment model considered the technical severity, occurrence probability, and detectability of the degradation factors.

The technical severity evaluation revealed that the ETICS construction process significantly alters the resilience of the system in regard to mechanical stability, long-term durability, ability to bypass tension, and weather protection. The preparation of substrate and application of adhesive are important factors, as are the activities that involve the reinforcement and finishing layer. The occurrence probability component reduced the relevance of the finishing layer, but added value to additionally 
added details (i.e., windowsills, plinth details). The detectability component was more relevant for the application of mixtures in the adhesive and reinforcement layers. The final output of the study, technical risk priority number (TRPN), emphasized that the most relevant aspect is the reinforcement layer for all ETICS types, and the significance of adhesion for the purely bonded system.

Based on the results of the study; the following general aspects should be considered during resource allocation for quality control:

1. The adhesion to the exterior façade of the building is highly relevant for the purely bonded ETICS. During the application process, the degradation factors which influence the adhesion characteristics have a very high impact on the technical severity of the system. These shortcomings are hard to detect as they are covered for further inspection shortly.

2. The preparation process of the reinforcement mixture and the application of the mesh have a high technical risk as shortcomings occur often. The layer is responsible for distributing internal and external stress. If a failure occurs, the anomalies evolve and enable moisture to penetrate the system.

3. The failures during the application of additional details (windowsills, fixed frames, plinth areas, and other fixings) often occur and have severe technical consequences but are detectable.

4. The failures that occur during construction in the insulation, anchorage, and finishing layers have reduced risk, as they occur rather rarely and are visually detectable. Nevertheless, the technical severity remains high for mechanical anchors.

The outcomes of the technical relevance model enable the allocation of resources on more relevant degradation factors, which occur often and are hard to detect, to avoid the loss of technical performance. In case of relevant changes to the requirements, construction technology, or construction materials, the developed model can be reapplied after the components are quantified according to the developed method.

Author Contributions: V.S. designed the study, collected and analyzed the data and wrote the paper. F.V. supervised and reviewed the paper.

Funding: This work was supported by institutional research funding of the Estonian Ministry of Education and Research IUT1-15 "Nearly-zero energy solutions and their implementation on deep renovation of buildings".

Acknowledgments: We would like to express our gratitude to the experts in Germany and Estonia who shared their experience and knowledge during this research.

Conflicts of Interest: The authors declare no conflict of interest. The funders had no role in the design of the study; in the collection, analyses, or interpretation of data; in the writing of the manuscript, and in the decision to publish the results. 


\section{Appendix A}

Table A1. Data for Equation (1)

\begin{tabular}{|c|c|c|c|c|c|c|c|c|c|c|c|c|c|c|c|c|c|c|}
\hline Sequence & ID & Layer & Description & ETICS 1 & ETICS 2 & ETICS 3 & SC1 & SC2 & SC3 & SC4 & SC5 & SC6 & SC7 & SC8 & sv & ov & DV & TRPN \\
\hline 1 & S1a & $\mathrm{s}$ & Substrate is covered with grease or oil & & $\mathrm{x}$ & $\mathrm{x}$ & 2.7 & 0.4 & 0.0 & 0.2 & 0.4 & 2.7 & 0.4 & 1.5 & 0.33 & 1.0 & 1.2 & 0.39 \\
\hline 2 & S1b & $\mathrm{s}$ & Substrate is covered with grease or oil & $\mathrm{x}$ & & & 4.3 & 0.3 & 0.0 & 0.2 & 0.3 & 3.3 & 0.3 & 1.8 & 0.46 & 1.0 & 1.4 & 0.64 \\
\hline 3 & S2a & $\mathrm{s}$ & Substrate is covered with dust or dirt & & $x$ & $x$ & 2.6 & 0.4 & 0.0 & 0.2 & 0.4 & 2.6 & 0.4 & 1.6 & 0.32 & 2.4 & 1.4 & 1.08 \\
\hline 4 & S2b & $\mathrm{s}$ & Substrate is covered with dust or dirt & $\mathrm{x}$ & & & 4.2 & 0.3 & 0.0 & 0.2 & 0.3 & 3.3. & 0.3 & 1.9 & 0.45 & 2.4 & 1.6 & 1.72 \\
\hline 5 & S3a & $\mathrm{s}$ & Substrate is covered with biological growth & & $\mathrm{x}$ & $\mathrm{x}$ & 2.6 & 0.4 & 0.0 & 0.2 & 0.4 & 2.6 & 0.4 & 1.5 & 0.32 & 2.8 & 1.6 & 1.43 \\
\hline 6 & S3b & $\mathrm{s}$ & Substrate is covered with biological growth & $\mathrm{x}$ & & & 3.9 & 0.4 & 0.0 & 0.2 & 0.4 & 3.5 & 0.4 & 2.1 & 0.45 & 3.0 & 1.6 & 2.14 \\
\hline 7 & S4a & $\mathrm{s}$ & Substrate is covered with paint or other material which can chemically react with adhesive & & $\mathrm{x}$ & $\mathrm{x}$ & 2.8 & 0.6 & 0.3 & 0.2 & 0.5 & 2.8 & 0.5 & 1.7 & 0.36 & 2.4 & 2.8 & 2.39 \\
\hline 8 & S4b & $\mathrm{s}$ & Substrate is covered with paint or other material which can chemically react with adhesive & $\mathrm{x}$ & & & 4.0 & 0.3 & 0.3 & 0.0 & 0.4 & 3.6 & 0.1 & 2.2 & 0.45 & 2.6 & 3.0 & 3.53 \\
\hline 9 & S5a & $\mathrm{s}$ & Substrate is under required load-bearing capacity & & $x$ & $x$ & 3.7 & 0.4 & 0.0 & 0.2 & 0.4 & 3.4 & 0.6 & 1.8 & 0.42 & 2.2 & 3.2 & 2.99 \\
\hline 10 & S5b & $\mathrm{s}$ & Substrate is under required load-bearing capacity & $\mathrm{x}$ & & & 4.0 & 0.4 & 0.0 & 0.2 & 0.4 & 3.6 & 0.6 & 2.1 & 0.46 & 1.6 & 3.4 & 2.49 \\
\hline 11 & S6a & $\mathrm{s}$ & Substrate has large unevenness or has detached areas & & $x$ & $\mathrm{x}$ & 2.1 & 0.3 & 0.6 & 0.3 & 0.4 & 2.0 & 0.6 & 1.2 & 0.26 & 3.6 & 1.8 & 1.69 \\
\hline 12 & S6b & $\mathrm{s}$ & Substrate has large unevenness or has detached areas & $\mathrm{x}$ & & & 2.9 & 0.3 & 0.6 & 0.3 & 0.4 & 2.4 & 0.6 & 1.3 & 0.33 & 3.0 & 1.6 & 1.60 \\
\hline 13 & S7a & s & Unsuitable surface (too smooth) which reduces adhesion properties & & $\mathrm{x}$ & $\mathrm{x}$ & 2.3 & 0.7 & 0.0 & 0.3 & 0.7 & 2.2 & 0.7 & 1.0 & 0.29 & 2.0 & 3.3 & 1.94 \\
\hline 14 & S7b & $\mathrm{s}$ & Unsuitable surface (too smooth) which reduces adhesion properties & $\mathrm{x}$ & & & 3.7 & 0.0 & 0.4 & 0.0 & 0.0 & 2.4 & 0.7 & 1.4 & 0.37 & 2.0 & 3.7 & 2.73 \\
\hline 15 & S8a & $\mathrm{S}$ & Substrate has very low humidity (inorganic adhesive) & & $x$ & $x$ & 2.5 & 0.4 & 0.0 & 0.2 & 0.5 & 2.5 & 0.8 & 1.6 & 0.31 & 2.3 & 2.5 & 1.73 \\
\hline 16 & S8b & $\mathrm{S}$ & Substrate has very low humidity (inorganic adhesive) & $x$ & & & 4.0 & 0.4 & 0.0 & 0.2 & 0.7 & 3.2 & 0.8 & 1.9 & 0.45 & 2.5 & 2.5 & 2.78 \\
\hline 17 & 59a & $\mathrm{S}$ & Substrate is very wet (raining in prior to application of adhesive) & & $x$ & $x$ & 2.4 & 0.5 & 0.3 & 0.2 & 0.7 & 2.4 & 0.7 & 1.3 & 0.31 & 2.2 & 1.8 & 1.21 \\
\hline 18 & S9b & $\mathrm{S}$ & Substrate is very wet (raining in prior to application of adhesive) & $x$ & & & 3.6 & 0.5 & 0.3 & 0.2 & 0.7 & 3.0 & 0.7 & 1.5 & 0.41 & 2.2 & 2.0 & 1.81 \\
\hline
\end{tabular}

Table A2. Data for Equation (2)

\begin{tabular}{|c|c|c|c|c|c|c|c|c|c|c|c|c|c|c|c|c|c|c|}
\hline Sequence & ID & Layer & Description & ETICS 1 & ETICS 2 & ETICS 3 & SC1 & SC2 & $\mathrm{SC} 3$ & SC4 & SC5 & SC6 & SC7 & SC8 & sv & ov & DV & TRPN \\
\hline 19 & S10a & $\mathrm{s}$ & Substrate is frozen during the application (inorganic adhesive) & & $\mathrm{x}$ & $\mathrm{x}$ & 4.0 & 0.2 & 0.4 & 0.0 & 0.0 & 3.8 & 0.0 & 2.2 & 0.45 & 1.4 & 2.2 & 1.39 \\
\hline 20 & s10b & $\mathrm{s}$ & Substrate is frozen during the application (inorganic adhesive) & $\mathrm{x}$ & & & 4.2 & 0.2 & 0.4 & 0.0 & 0.0 & 4.2 & 0.0 & 2.2 & 0.48 & 1.4 & 2.2 & 1.47 \\
\hline 21 & M1a & $\mathrm{D}$ & Unsuitable mixture storage conditions & & $\mathrm{x}$ & $\mathrm{x}$ & 2.8 & 0.0 & 0.0 & 0.0 & 0.0 & 2.6 & 0.0 & 1.5 & 0.30 & 0.8 & 3.0 & 0.72 \\
\hline 22 & M1b & $\mathrm{D}$ & Unsuitable mixture storage conditions & $\mathrm{x}$ & & & 4.0 & 0.0 & 0.0 & 0.0 & 0.0 & 3.6 & 0.0 & 1.8 & 0.42 & 0.8 & 3.0 & 1.02 \\
\hline 23 & $\mathrm{M} 2 \mathrm{a}$ & $\mathrm{D}$ & The mixing procedures do not remove clots & & $\mathrm{x}$ & $\mathrm{x}$ & 2.1 & 0.0 & 0.0 & 0.0 & 0.0 & 1.6 & 0.0 & 0.4 & 0.21 & 1.4 & 2.6 & 0.75 \\
\hline 24 & $\mathrm{M} 2 \mathrm{~b}$ & $\mathrm{D}$ & The mixing procedures do not remove clots & $\mathrm{x}$ & & & 2.6 & 0.0 & 0.0 & 0.0 & 0.0 & 2.0 & 0.0 & 0.8 & 0.26 & 1.2 & 2.6 & 0.81 \\
\hline 25 & M3a & $\mathrm{D}$ & High share of kneading water & & $\mathrm{x}$ & $\mathrm{x}$ & 2.4 & 0.3 & 0.0 & 0.2 & 0.7 & 2.2 & 0.4 & 1.0 & 0.28 & 1.4 & 3.0 & 1.19 \\
\hline 26 & M3b & $\mathrm{D}$ & High share of kneading water & $\mathrm{x}$ & & & 3.2 & 0.3 & 0.0 & 0.2 & 0.8 & 2.4 & 0.4 & 1.2 & 0.35 & 1.8 & 3.0 & 1.90 \\
\hline 27 & M4a & $\mathrm{D}$ & Low share of kneading water & & $\mathrm{x}$ & $\mathrm{x}$ & 2.6 & 0.4 & 0.0 & 0.3 & 1.0 & 2.4 & 0.5 & 1.1 & 0.31 & 1.5 & 3.0 & 1.40 \\
\hline 28 & $\mathrm{M} 4 \mathrm{~b}$ & $\mathrm{D}$ & Low share of kneading water & $\mathrm{x}$ & & & 3.1 & 0.0 & 0.0 & 0.0 & 0.7 & 2.3 & 0.0 & 1.6 & 0.33 & 1.5 & 3.0 & 1.47 \\
\hline 29 & D1a & $\mathrm{D}$ & Missing adhesive on the edges of insulation (polystyrene) & & $\mathrm{x}$ & & 2.3 & 1.6 & 2.2 & 1.1 & 1.6 & 3.0 & 0.6 & 1.7 & 0.40 & 1.5 & 3.3 & 1.97 \\
\hline 30 & D1b & $\mathrm{D}$ & Missing adhesive on the edges of insulation (polystyrene) & $\mathrm{x}$ & & & 3.3 & 1.5 & 2.0 & 1.0 & 1.7 & 3.4 & 0.5 & 1.5 & 0.47 & 1.5 & 3.3 & 2.30 \\
\hline 31 & D2a & $\mathrm{D}$ & Missing adhesive in the center of insulation (polystyrene) & & $\mathrm{x}$ & & 2.4 & 0.4 & 0.3 & 0.3 & 1.2 & 2.7 & 0.7 & 1.1 & 0.32 & 1.3 & 2.8 & 1.09 \\
\hline 32 & $\mathrm{D} 2 \mathrm{~b}$ & $\mathrm{D}$ & Missing adhesive in the center of insulation (polystyrene) & $\mathrm{x}$ & & & 3.3 & 0.4 & 0.3 & 0.3 & 1.5 & 3.2 & 0.6 & 1.3 & 0.40 & 1.3 & 2.8 & 1.36 \\
\hline 33 & D3a & $\mathrm{D}$ & Insufficient adhesive surface area & & $\mathrm{x}$ & $\mathrm{x}$ & 2.6 & 1.9 & 1.0 & 0.5 & 0.6 & 3.1 & 0.3 & 1.9 & 0.41 & 2.8 & 2.5 & 2.84 \\
\hline 34 & D3b & $\mathrm{D}$ & Insufficient adhesive surface area & $\mathrm{x}$ & & & 3.2 & 0.9 & 0.7 & 0.4 & 0.3 & 2.9 & 0.2 & 1.2 & 0.39 & 2.8 & 2.5 & 2.67 \\
\hline 35 & D4 & $\mathrm{D}$ & Adhesive is not rubbed into insulation plate (mineral wool) & & & $\mathrm{x}$ & 2.4 & 0.0 & 0.0 & 0.0 & 0.6 & 2.6 & 0.0 & 1.2 & 0.28 & 2.0 & 3.0 & 1.66 \\
\hline 36 & D5 & $\mathrm{D}$ & Adhesive is not treated with notch towel (mineral wool) & & & $\mathrm{x}$ & 2.9 & 0.5 & 0.4 & 0.0 & 0.1 & 1.9 & 0.1 & 1.1 & 0.31 & 2.3 & 3.0 & 2.14 \\
\hline
\end{tabular}


Table A3. Data for Equation (3).

\begin{tabular}{|c|c|c|c|c|c|c|c|c|c|c|c|c|c|c|c|c|c|c|}
\hline Sequence & ID & Layer & Description & ETICS 1 & ETICS 2 & ETICS 3 & SC1 & $\mathrm{SC} 2$ & SC3 & SC4 & SC5 & SC6 & SC7 & SC8 & sv & ov & DV & TRPN \\
\hline 37 & D7a & $\mathrm{D}$ & Working time of the adhesive is exceeded & & $\mathrm{x}$ & $\mathrm{x}$ & 2.8 & 0.5 & 0.3 & 0.2 & 0.3 & 2.7 & 0.3 & 1.7 & 0.34 & 1.8 & 2.6 & 1.60 \\
\hline 38 & D7b & $\mathrm{D}$ & Working time of the adhesive is exceeded & $\mathrm{x}$ & & & 4.0 & 0.5 & 0.3 & 0.2 & 0.3 & 3.3 & 0.3 & 1.9 & 0.44 & 1.8 & 2.8 & 2.24 \\
\hline 39 & D8a & $\mathrm{D}$ & Low pressure during application of insulation plates & $x^{\prime}$ & $\mathrm{x}$ & $\mathrm{x}$ & 1.9 & 0.6 & 0.3 & 0.3 & 0.4 & 2.1 & 0.4 & 1.0 & 0.25 & 2.7 & 3.0 & 2.02 \\
\hline 40 & D8b & $\mathrm{D}$ & Low pressure during application of insulation plates & $\mathrm{x}$ & & & 3.4 & 0.8 & 0.4 & 0.2 & 0.3 & 2.7 & 0.3 & 1.6 & 0.40 & 2.0 & 3.0 & 2.38 \\
\hline 41 & D9a & $\mathrm{D}$ & Large unevenness of the adhesive layer & & $\mathrm{x}$ & $\mathrm{x}$ & 1.9 & 0.4 & 0.4 & 0.3 & 0.1 & 1.8 & 0.0 & 1.3 & 0.23 & 1.7 & 3.5 & 1.35 \\
\hline 42 & D9b & $\mathrm{D}$ & Large unevenness of the adhesive layer & $\mathrm{x}$ & & & 2.9 & 0.4 & 0.4 & 0.3 & 0.1 & 2.4 & 0.0 & 1.3 & 0.32 & 1.7 & 3.5 & 1.87 \\
\hline 43 & м9а & $\mathrm{D}$ & Low temperature (freezing) during application and/or curing process & & $\mathrm{x}$ & $\mathrm{x}$ & 3.5 & 0.4 & 0.0 & 0.1 & 1.1 & 3.2 & 0.4 & 2.5 & 0.42 & 1.4 & 2.2 & 1.31 \\
\hline 44 & M9b & $\mathrm{D}$ & Low temperature (freezing) during application and/or curing process & $\mathrm{x}$ & & & 4.6 & 0.4 & 0.0 & 0.1 & 1.3 & 3.7 & 0.4 & 2.7 & 0.52 & 1.6 & 2.4 & 2.01 \\
\hline 45 & M10a & D & High temperature (hot) during curing process & & $\mathrm{x}$ & $\mathrm{x}$ & 2.6 & 0.3 & 0.0 & 0.1 & 0.5 & 2.3 & 0.2 & 1.7 & 0.31 & 1.8 & 2.6 & 1.43 \\
\hline 46 & M10b & $\mathrm{D}$ & High temperature (hot) during curing process & $\mathrm{x}$ & & & 3.6 & 0.3 & 0.0 & 0.1 & 0.8 & 3.0 & 0.2 & 1.9 & 0.40 & 1.8 & 2.6 & 1.89 \\
\hline 47 & M11a & $\mathrm{D}$ & Low humidity (dry) during curing process & & $\mathrm{x}$ & $\mathrm{x}$ & 2.6 & 0.0 & 0.0 & 0.0 & 0.4 & 1.9 & 0.0 & 1.0 & 0.26 & 2.3 & 3.0 & 1.82 \\
\hline 48 & M11b & $\mathrm{D}$ & Low humidity (dry) during curing process & $\mathrm{x}$ & & & 3.7 & 0.0 & 0.0 & 0.0 & 0.4 & 2.4 & 0.0 & 1.4 & 0.37 & 2.3 & 3.0 & 2.56 \\
\hline 49 & M8 & $\mathrm{D}$ & Not recommended ingredients added to the mixture & $\mathrm{x}$ & $\mathrm{x}$ & $\mathrm{x}$ & 3.4 & 0.9 & 0.0 & 0.0 & 1.9 & 3.9 & 0.0 & 2.9 & 0.47 & 1.8 & 2.6 & 2.18 \\
\hline 50 & $\mathrm{I} 1$ & & Polystyrene is exposed to ultraviolet (UV)-radiation for an extended period & $\mathrm{x}$ & $\mathrm{x}$ & & 3.3 & 0.4 & 0.2 & 0.1 & 0.9 & 3.3 & 0.7 & 1.6 & 0.40 & 1.3 & 1.4 & 0.70 \\
\hline 51 & I2 & I & Insulation plates are installed shortly after manufacturing (unfinished diffusion process & $\mathrm{x}$ & $\mathrm{x}$ & & 1.4 & 0.4 & 0.8 & 0.5 & 1.0 & 2.8 & 0.4 & 2.1 & 0.26 & 1.8 & 3.5 & 1.61 \\
\hline 52 & I3a & I & Mineral wool insulation plates have very high relative humidity (are wet & & & $\mathrm{x}$ & 2.4 & 0.3 & 2.4 & 0.3 & 1.3 & 2.1 & 0.8 & 0.9 & 0.30 & 1.2 & 2.4 & 0.87 \\
\hline 53 & I3b & I & Insulation plates which have very high relative humidity (wet) & $\mathrm{x}$ & $\mathrm{x}$ & & 0.8 & 0.6 & 1.4 & 0.2 & 1.0 & 0.6 & 0.8 & 0.2 & 0.14 & 1.5 & 3.0 & 0.61 \\
\hline 54 & I4 & $\mathrm{I}$ & Continuous gaps between substrate and insulation material & $x$ & $\mathrm{x}$ & $\mathrm{x}$ & 2.2 & 3.3 & 4.3 & 2.2 & 2.1 & 3.7 & 2.0 & 1.3 & 0.53 & 1.4 & 3.2 & 2.38 \\
\hline
\end{tabular}

Table A4. Data for Equation (4).

\begin{tabular}{|c|c|c|c|c|c|c|c|c|c|c|c|c|c|c|c|c|c|c|}
\hline Sequence & ID & Layer & Description & ETICS 1 & ETICS 2 & ETICS 3 & SC1 & SC2 & SC3 & SC4 & SC5 & SC6 & SC7 & SC8 & SV & OV & DV & TRPN \\
\hline 55 & I5 & I & Corners of neighboring insulation plates are crossed or too close & $\mathrm{x}$ & $\mathrm{x}$ & $\mathrm{x}$ & 1.0 & 0.1 & 1.0 & 0.3 & 1.8 & 2.7 & 0.2 & 2.1 & 0.23 & 2.3 & 1.3 & 0.65 \\
\hline 56 & I6 & I & Corners of the openings have crossed joints & $\mathrm{x}$ & $\mathrm{x}$ & $\mathrm{x}$ & 1.4 & 0.1 & 1.3 & 0.1 & 2.2 & 3.1 & 0.5 & 2.3 & 0.28 & 2.8 & 1.2 & 0.93 \\
\hline 57 & I7 & I & Insulation plates joint width of neighboring insulation plates is too wide & $\mathrm{x}$ & $\mathrm{x}$ & $\mathrm{x}$ & 1.0 & 0.0 & 2.0 & 0.6 & 1.6 & 2.4 & 0.4 & 1.0 & 0.21 & 1.5 & 1.0 & 0.31 \\
\hline 58 & I8 & I & Large height difference between neighboring insulation plates & $\mathrm{x}$ & $\hat{x}$ & $\mathrm{x}$ & 0.6 & 0.1 & 0.8 & 0.3 & 1.8 & 2.6 & 0.5 & 1.8 & 0.20 & 2.0 & 2.0 & 0.78 \\
\hline 59 & I9 & I & Broken areas of the insulation plates are not filled with same material & $\mathrm{x}$ & $\mathrm{x}$ & $\mathrm{x}$ & 1.0 & 0.6 & 1.8 & 1.0 & 1.6 & 1.9 & 0.0 & 1.2 & 0.22 & 2.3 & 1.3 & 0.61 \\
\hline 60 & I10 & I & Missing or narrow fire reluctant areas & $\hat{x}$ & $\hat{x}$ & & 0.1 & 4.9 & 0.1 & 0.1 & 0.1 & 0.3 & 0.1 & 0.1 & 0.22 & 1.5 & 1.3 & 0.41 \\
\hline 61 & A1 & A & Increased diameter of drilled anchor hole & & $\mathrm{x}$ & $\mathrm{x}$ & 4.0 & 0.7 & 0.3 & 0.2 & 0.6 & 2.4 & 0.3 & 1.4 & 0.42 & 1.5 & 3.0 & 1.91 \\
\hline 62 & A10 & A & Hole of the anchor is not cleaned & & $\mathrm{x}$ & $\mathrm{x}$ & 2.3 & 0.3 & 0.0 & 0.0 & 0.0 & 1.5 & 0.0 & 0.7 & 0.24 & 1.3 & 2.3 & 0.73 \\
\hline 63 & A5 & A & Location of anchors is not as foreseen & & $\begin{array}{l}x \\
x\end{array}$ & $\begin{array}{l}x \\
x\end{array}$ & 2.5 & 0.5 & 0.0 & 0.1 & 0.1 & 1.4 & 0.0 & 1.1 & 0.26 & 1.7 & 1.3 & 0.58 \\
\hline 64 & A3 & A & Decreased number of anchors in the continuous areas & & $\mathrm{x}$ & $\mathrm{x}$ & 3.5 & 0.4 & 0.1 & 0.1 & 0.1 & 2.3 & 0.0 & 1.1 & 0.36 & 2.5 & 1.3 & 1.11 \\
\hline 65 & A8 & A & Decreased number of anchors in the corner areas & & $\mathrm{x}$ & $\mathrm{x}$ & 3.6 & 0.6 & 0.2 & 0.1 & 0.6 & 2.6 & 0.4 & 1.6 & 0.39 & 1.7 & 1.3 & 0.87 \\
\hline 66 & A9 & A & Usage of unsuitable anchor type & & $\mathrm{x}$ & $\mathrm{x}$ & 4.2 & 0.6 & 0.1 & 0.1 & 0.5 & 2.9 & 0.4 & 1.8 & 0.45 & 2.2 & 2.4 & 2.39 \\
\hline 67 & A2 & A & Decreased diameter of anchor plate & & $\mathrm{x}$ & $\mathrm{x}$ & 3.4 & 0.3 & 0.1 & 0.1 & 0.3 & 2.1 & 0.2 & 0.9 & 0.34 & 1.3 & 1.0 & 0.45 \\
\hline 68 & A6 & A & Anchor plate is installed too deeply into insulation material & & $x$ & $\mathrm{x}$ & $\begin{array}{l}3.4 \\
1.1\end{array}$ & 0.1 & 1.0 & 0.3 & 1.6 & 2.6 & 0.2 & 1.4 & 0.22 & 2.4 & 1.0 & 0.53 \\
\hline 69 & A7 & A & Anchor plate is placed too high on the surface of insulation material & & $\mathrm{x}$ & $\mathrm{x}$ & 1.7 & 0.1 & 0.4 & 0.2 & 1.0 & 2.4 & 0.3 & 1.6 & 0.25 & 1.8 & 1.0 & 0.43 \\
\hline 70 & R1 & $\mathrm{R}$ & External layer of the insulation plate is too smooth, reduced adhesion & $\mathrm{x}$ & $\mathrm{x}$ & & 3.5 & 0.0 & 0.0 & 0.0 & 1.7 & 3.3 & 0.7 & 1.3 & 0.40 & 2.0 & 3.0 & 2.37 \\
\hline 71 & M1c & $\mathrm{R}$ & $\begin{array}{l}\text { Unsuitable material storage conditions } \\
\text { S }\end{array}$ & $\hat{x}$ & $\hat{x}$ & $\mathrm{x}$ & 4.0 & 0.0 & 0.0 & 0.0 & 2.6 & 4.3 & 0.0 & 3.0 & 0.49 & 1.0 & 3.0 & 1.48 \\
\hline 72 & $\mathrm{M} 2 \mathrm{c}$ & $\mathrm{R}$ & The mixing procedures do not remove clots & $\mathrm{x}$ & $\mathrm{x}$ & $\mathrm{x}$ & 31 & 00 & 00 & 00 & 21 & 33 & 00 & 26 & 039 & 12 & 22 & 1.03 \\
\hline
\end{tabular}


Table A5. Data for Equation (5).

\begin{tabular}{|c|c|c|c|c|c|c|c|c|c|c|c|c|c|c|c|c|c|c|}
\hline Sequence & ID & Layer & Description & ETICS 1 & ETICS 2 & ETICS 3 & SC1 & SC2 & SC3 & SC4 & SC5 & SC6 & SC7 & SC8 & sv & ov & DV & TRPN \\
\hline 72 & $\mathrm{M} 2 \mathrm{c}$ & $\mathrm{R}$ & The mixing procedures do not remove clots & $\mathrm{x}$ & $\mathrm{x}$ & $\mathrm{x}$ & 3.1 & 0.0 & 0.0 & 0.0 & 2.1 & 3.3 & 0.0 & 2.6 & 0.39 & 1.2 & 2.2 & 1.03 \\
\hline 73 & M3c & $\mathrm{R}$ & High share of kneading water & $\mathrm{x}$ & $\mathrm{x}$ & $\mathrm{x}$ & 3.8 & 0.0 & 0.3 & 0.0 & 2.9 & 3.8 & 0.3 & 3.0 & 0.47 & 1.8 & 2.2 & 1.86 \\
\hline 74 & M4c & $\mathrm{R}$ & Low share of kneading water & $\mathrm{x}$ & $\mathrm{x}$ & $\mathrm{x}$ & 3.1 & 0.4 & 0.0 & 0.1 & 2.4 & 3.2 & 0.4 & 2.8 & 0.42 & 1.4 & 2.6 & 1.52 \\
\hline 75 & R6 & $\mathrm{R}$ & Thin mortar layer & $\mathrm{x}$ & $\mathrm{x}$ & $x$ & 3.0 & 2.5 & 1.1 & 1.3 & 3.6 & 4.3 & 1.0 & 3.6 & 0.58 & 2.8 & 2.0 & 3.19 \\
\hline 76 & R2 & $\mathrm{R}$ & Decreased overlap of the mesh & $\mathrm{x}$ & $\mathrm{x}$ & $\mathrm{x}$ & 2.2 & 0.7 & 0.4 & 0.1 & 1.7 & 3.2 & 0.8 & 2.4 & 0.36 & 1.8 & 3.0 & 1.88 \\
\hline 77 & R3 & $\mathrm{R}$ & Folded mesh & $\mathrm{x}$ & $\mathrm{x}$ & $\mathrm{x}$ & 1.4 & 0.4 & 0.4 & 0.0 & 0.9 & 2.6 & 0.4 & 2.1 & 0.25 & 1.0 & 2.5 & 0.64 \\
\hline 78 & R4 & $\mathrm{R}$ & Missing diagonal mesh & $\mathrm{x}$ & $\mathrm{x}$ & $\mathrm{x}$ & 2.1 & 0.5 & 0.4 & 0.0 & 1.2 & 3.1 & 0.6 & 2.3 & 0.33 & 2.0 & 2.5 & 1.64 \\
\hline 79 & R5 & $\mathrm{R}$ & Mesh not filled with mortar, placed on the edge of the layer & $\mathrm{x}$ & $\mathrm{x}$ & $\mathrm{x}$ & 3.0 & 0.7 & 0.1 & 0.4 & 1.9 & 3.6 & 0.0 & 2.1 & 0.41 & 2.0 & 2.3 & 1.93 \\
\hline 80 & R7 & $\mathrm{R}$ & Layer is not applied in wet to wet conditions & $\mathrm{x}$ & $\mathrm{x}$ & $\mathrm{x}$ & 2.6 & 0.0 & 0.3 & 0.0 & 2.3 & 3.0 & 0.4 & 2.7 & 0.35 & 2.5 & 3.0 & 2.66 \\
\hline 81 & R8 & $\mathrm{R}$ & Usage of not compatible mesh & $\mathrm{x}$ & $\mathrm{x}$ & $\mathrm{x}$ & 3.2 & 0.9 & 0.4 & 0.0 & 1.4 & 3.9 & 0.5 & 2.9 & 0.46 & 1.4 & 3.0 & 1.92 \\
\hline 82 & M9c & $\mathrm{R}$ & Low temperature (freezing) during application and/or curing process & $\mathrm{x}$ & $\mathrm{x}$ & $\mathrm{x}$ & 4.8 & 0.8 & 0.3 & 0.3 & 3.3 & 4.7 & 0.6 & 4.0 & 0.63 & 1.8 & 1.8 & 2.05 \\
\hline 83 & M10c & $\mathrm{R}$ & High temperature (hot) curing conditions & $\mathrm{x}$ & $\mathrm{x}$ & $\mathrm{x}$ & 3.5 & 0.3 & 0.0 & 0.1 & 2.5 & 3.6 & 0.4 & 2.8 & 0.45 & 2.2 & 1.8 & 1.77 \\
\hline $\begin{array}{l}84 \\
85\end{array}$ & $\begin{array}{l}\text { M11c } \\
\text { M12c }\end{array}$ & ${ }_{\mathrm{R}}^{\mathrm{R}}$ & $\begin{array}{l}\text { Low humidity (dry) curing conditions } \\
\text { Usage of winter mixtures during unsuitable weather conditions }\end{array}$ & $\begin{array}{l}x \\
x\end{array}$ & $\begin{array}{l}x \\
x\end{array}$ & $\begin{array}{l}x \\
x\end{array}$ & 3.5 & $\begin{array}{l}0.0 \\
0.0\end{array}$ & $\begin{array}{l}0.0 \\
0.0\end{array}$ & 0.0 & 3.0 & 3.6 & $\begin{array}{l}0.0 \\
0.0\end{array}$ & $\begin{array}{l}3.1 \\
18\end{array}$ & 0.45 & $\begin{array}{l}2.0 \\
10\end{array}$ & $\begin{array}{l}1.5 \\
30\end{array}$ & 1.34 \\
\hline 85 & M12c & & 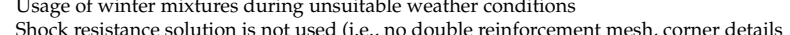 & & & & 2.4 & 0.0 & & 0.0 & 2.6 & 3.2 & & 1.8 & 0.33 & 1.0 & 3.0 & 0.98 \\
\hline 86 & $\mathrm{X} 6$ & $\mathrm{x}$ & $\begin{array}{l}\text { with metal or additional protective plate installed) } \\
\text { and }\end{array}$ & $\mathrm{x}$ & $\mathrm{x}$ & $\mathrm{x}$ & 1.9 & 0.3 & 0.1 & 0.4 & 1.4 & 3.7 & 0.2 & 1.1 & 0.30 & 2.6 & 2.0 & 1.56 \\
\hline 87 & F2 & $\mathrm{F}$ & $\begin{array}{l}\text { With metal or addittonal protective plate enstallea) } \\
\text { Reinforcement mixture or primary coat is not cured }\end{array}$ & $\mathrm{x}$ & $\mathrm{x}$ & $\mathrm{x}$ & 1.7 & 0.0 & 0.2 & 0.0 & 1.8 & 2.8 & 0.6 & 1.3 & 0.25 & 2.0 & 3.0 & 1.51 \\
\hline 88 & F1 & $\mathrm{F}$ & Missing primer if required & $\mathrm{x}$ & $\mathrm{x}$ & $\mathrm{x}$ & 1.5 & 0.1 & 0.2 & 0.0 & 1.5 & 2.5 & 0.2 & 0.8 & 0.22 & 1.4 & 2.2 & 0.67 \\
\hline 89 & M1d & $\mathrm{F}$ & Unsuitable material storage conditions & $\mathrm{x}$ & $\mathrm{x}$ & $\mathrm{x}$ & 4.3 & 0.4 & 0.0 & 0.1 & 3.4 & 4.4 & 0.9 & 2.9 & 0.56 & 1.0 & 2.6 & 1.45 \\
\hline 90 & $\mathrm{M} 2 \mathrm{~d}$ & $\mathrm{~F}$ & The mixing procedures do not remove clots & $x$ & $x$ & & 3.6 & 0.0 & 0.0 & 0.0 & 3.4 & 3.8 & 1.0 & 2.2 & 0.45 & 1.0 & 2.0 & 0.91 \\
\hline 91 & M3d & $\mathrm{F}$ & High share of kneading water & $x$ & $x$ & $x$ & 3.2 & 0.7 & 0.3 & 0.2 & 4.3 & 4.5 & 1.2 & 3.3 & 0.51 & 0.5 & 1.7 & 0.43 \\
\hline
\end{tabular}

Table A6. Data for Equation (6).

\begin{tabular}{|c|c|c|c|c|c|c|c|c|c|c|c|c|c|c|c|c|c|c|}
\hline Sequence & ID & Layer & Description & ETICS 1 & ETICS 2 & ETICS 3 & SC1 & SC2 & $\mathrm{SC} 3$ & SC4 & SC5 & SC6 & SC7 & SC8 & SV & OV & DV & TRPN \\
\hline 91 & M3d & $\mathrm{F}$ & High share of kneading water & $\mathrm{x}$ & $\mathrm{x}$ & $\mathrm{x}$ & 3.2 & 0.7 & 0.3 & 0.2 & 4.3 & 4.5 & 1.2 & 3.3 & 0.51 & 0.5 & 1.7 & 0.43 \\
\hline 92 & F3 & $\mathrm{F}$ & Thick render layer/differences in thickness & $\mathrm{x}$ & $\mathrm{x}$ & $\mathrm{x}$ & 0.9 & 0.1 & 0.7 & 0.4 & 1.3 & 2.3 & 0.1 & 1.1 & 0.18 & 0.7 & 3.0 & 0.37 \\
\hline 93 & $\mathrm{~F} 4$ & F & Thin render layer & $\mathrm{x}$ & $\mathrm{x}$ & $\mathrm{x}$ & 1.6 & 0.6 & 0.7 & 0.6 & 2.6 & 2.7 & 0.4 & 1.3 & 0.28 & 1.5 & 1.7 & 0.71 \\
\hline 94 & M9d & F & Low temperature (freezing) during application and/or curing process & $\mathrm{x}$ & $\mathrm{x}$ & $\mathrm{x}$ & 4.5 & 0.5 & 0.3 & 0.4 & 3.4 & 4.7 & 0.6 & 3.4 & 0.60 & 1.5 & 1.0 & 0.89 \\
\hline 95 & M10d & $\mathrm{F}$ & High temperature (hot) curing conditions & $\mathrm{x}$ & $\mathrm{x}$ & $\mathrm{x}$ & 3.5 & 0.3 & 0.0 & 0.1 & 2.5 & 3.5 & 0.3 & 2.5 & 0.44 & 2.2 & 1.4 & 1.35 \\
\hline 96 & M11d & $\mathrm{F}$ & Low humidity (dry) curing conditions & $\mathrm{x}$ & $\mathrm{x}$ & $\mathrm{x}$ & 3.6 & 0.0 & 0.0 & 0.0 & 3.0 & 3.6 & 0.0 & 2.6 & 0.45 & 2.5 & 1.5 & 1.67 \\
\hline 97 & $\mathrm{x} 1$ & $\mathrm{x}$ & Structural expansion joint is not installed/finished properly & $\mathrm{x}$ & $\mathrm{x}$ & $\mathrm{x}$ & 1.5 & 0.3 & 0.5 & 0.3 & 2.0 & 2.8 & 0.3 & 3.0 & 0.29 & 1.4 & 1.8 & 0.72 \\
\hline 98 & $\mathrm{x} 2$ & $\mathrm{x}$ & Windowsill not appropriately finished (i.e., curved upwards, proper sealants) & $\mathrm{x}$ & $\mathrm{x}$ & $\mathrm{x}$ & 2.1 & 0.6 & 1.1 & 0.3 & 4.0 & 4.1 & 1.1 & 1.7 & 0.39 & 3.6 & 1.6 & 2.26 \\
\hline 99 & $\mathrm{X} 3$ & $\mathrm{x}$ & Unsolved rainwater drainage (i.e., drainpipe or drip profiles not used) & $\mathrm{x}$ & $\mathrm{x}$ & $\mathrm{x}$ & 2.6 & 0.3 & 2.0 & 0.1 & 4.3 & 4.3 & 2.3 & 2.6 & 0.46 & 3.0 & 1.2 & 1.65 \\
\hline 100 & $\mathrm{X} 4$ & $\mathrm{x}$ & Fixed frame connection is not finished accurately (i.e., missing sealants) & $\mathrm{x}$ & $\mathrm{x}$ & $\mathrm{x}$ & 1.6 & 0.5 & 1.7 & 0.5 & 3.5 & 3.5 & 0.9 & 1.5 & 0.33 & 3.2 & 1.8 & 1.92 \\
\hline 101 & X5 & $\mathrm{x}$ & Roof edge covers are not installed correctly (i.e., vertical detail too short) & $\mathrm{x}$ & $\mathrm{x}$ & $\mathrm{x}$ & 1.0 & 0.1 & 0.9 & 0.1 & 2.9 & 3.3 & 0.6 & 0.4 & 0.23 & 2.6 & 2.0 & 1.17 \\
\hline 102 & $\mathrm{X} 7$ & $\mathrm{x}$ & Unfinished penetrations through the system (i.e., fixed without sealants) & $\mathrm{x}$ & $x$ & $x$ & 1.8 & 1.3 & 1.4 & 0.8 & 3.9 & 3.9 & 1.3 & 1.4 & 0.39 & 3.4 & 1.2 & 1.59 \\
\hline 103 & $\mathrm{x} 8$ & $\mathrm{x}$ & Unsuitable plinth detail solutions (i.e., incorrect fixing, overlapping of details) & $\mathrm{x}$ & $\mathrm{x}$ & $\mathrm{x}$ & 1.7 & 0.3 & 0.8 & 0.1 & 2.7 & 3.0 & 0.4 & 1.0 & 0.28 & 2.6 & 1.4 & 1.02 \\
\hline
\end{tabular}




\section{References}

1. Housing Statistics in the European Union 2005/2006; Italian Housing Federation: Rome, Italy 2006.

2. Amaro, B.; Saraiva, D.; de Brito, J.; Flores-Colen, I. Statistical survey of the pathology, diagnosis and rehabilitation of ETICS in walls. J. Civ. Eng. Manag. 2014, 20,1-16. [CrossRef]

3. Künzel, H.; Künzel, H.M.; Sedlbauer, K. Long-term performance of external thermal insulation systems (ETICS). ACTA Archit. 2006, 5, 11-24.

4. Sulakatko, V.; Lill, I.; Liisma, E. Analysis of On-site Construction Processes for Effective External Thermal Insulation Composite System (ETICS) Installation. Procedia Econ. Financ. 2015, 21, 297-305. [CrossRef]

5. Schäden beim Energieeffizienten Bauen; Institute for Building Research (Institut für Bauforschung) e. V.: Hannover, Germany, 2011.

6. Neumann, H.-H. Praxis Handbuch Wärmedämm-Verbundsysteme. Baustoffkunde, Verarbeitung, Schäden, Sanierung; Rudolf Müller: Cologne, Germany, 2009.

7. Amaro, B.; Saraiva, D.; De Brito, J.; Flores-Colen, I. Inspection and diagnosis system of ETICS on walls. Constr. Build. Mater. 2013, 47, 1257-1267. [CrossRef]

8. Silva, J.A.R.M.; Falorca, J. A model plan for buildings maintenance with application in the performance analysis of a composite facade cover. Constr. Build. Mater. 2009, 23, 3248-3257. [CrossRef]

9. Cziesielski, E.; Vogdt, F.U. Schäden an Wärmedämm-Verbundsystemen, 2nd ed.; Fraunhofer IRB: Stuttgart, Germany, 2007.

10. Kussauer, R.; Ruprecht, M. Die Häufigsten Mängel bei Beschichtungen und WDVS, 2nd ed.; Rudolf Müller $\mathrm{GmbH} \&$ Co. KG: Cologne, Germany, 2011.

11. Arizzi, A.; Viles, H.; Cultrone, G. Experimental testing of the durability of lime-based mortars used for rendering historic buildings. Constr. Build. Mater. 2012, 28, 807-818. [CrossRef]

12. Nilica, R.; Harmuth, H. Mechanical and fracture mechanical characterization of building materials used for external thermal insulation composite systems. Cem. Concr. Res. 2005, 35, 1641-1645. [CrossRef]

13. Zirkelbach, D.; Künzel, H.M.; Slanina, P. Einfluss von Undichtheiten bei der Sanierung von Plattenbauten mit Wärmedämm-Verbundsystemen. WTA-Almanach 2008, 285-297. Available online: https:/ / www.ibp.fraunhofer.de/content/dam/ibp/de/documents/Publikationen/Fachzeitschriften/ FZ_4_tcm45-309231.pdf (accessed on 20 October 2018).

14. Fernandes, L.; Silva, V.; Ferreira, V.M.; Labrincha, J.A. Influence of the kneading water content in the behaviour of single-coat mortars. Cem. Concr. Res. 2005, 35, 1900-1908. [CrossRef]

15. Fernandes, V.; Silva, L.; Ferreira, V.M.; Labrincha, J.A. Evaluation of mixing and application process parameters of single-coat mortars. Cem. Concr. Res. 2005, 35, 836-841. [CrossRef]

16. Šadauskiene, J.; Stankevičius, V.; Bliudžius, R.; Gailius, A. The impact of the exterior painted thin-layer render's water vapour and liquid water permeability on the moisture state of the wall insulating system. Constr. Build. Mater. 2009, 23, 2788-2794.

17. Sedlbauer, K.; Krus, M. Mold growth on ETICS (EIFS) as a result of 'bad workmanship'? J. Therm. Envel. Build. Sci. 2002, 26, 117-121. [CrossRef]

18. Rhee, S.J.; Ishii, K. Using cost based FMEA to enhance reliability and serviceability. Adv. Eng. Inform. 2003, 17, 179-188. [CrossRef]

19. Carbone, T.A.; Tippett, D.D. Project Risk Management Using the Project Risk FMEA. Eng. Manag. J. 2004, 16, 28-35. [CrossRef]

20. Mecca, S.; Masera, M. Technical Risk Analysis in Construction By Means of Fmea Methodology. In Proceedings of the 15th Annual ARCOM Conference, Liverpool, UK, 15-17 September 1999.

21. Abdelgawad, M.; Fayek, A. Risk Management in the Construction Industry Using Combined Fuzzy FMEA and Fuzzy AHP. Eng. Manag. 2010, 136, 1028-1037. [CrossRef]

22. Puente, J.; Pino, R.; Priore, P.; de la Fuente, D. A decision support system for applying failure mode and effects analysis. Int. J. Qual. Reliab. Manag. 2002, 19, 137-150. [CrossRef]

23. Bowles, J.B. An assessment of RPN prioritization in a failure modes effects and criticality analysis. In Annual Reliability and Maintainability Symposium; IEEE: Tampa, FL, USA, 2003. [CrossRef]

24. Pillay, A.; Wang, J. Modified failure mode and effects analysis using approximate reasoning. Reliab. Eng. Syst. Saf. 2003, 79, 69-85. [CrossRef] 
25. Carmignani, G. An integrated structural framework to cost-based FMECA: The priority-cost FMECA. Reliab. Eng. Syst. Saf. 2009, 94, 861-871. [CrossRef]

26. Shafiee, M.; Dinmohammadi, F. An FMEA-based risk assessment approach for wind turbine systems: A comparative study of onshore and offshore. Energies 2014, 7, 619-642. [CrossRef]

27. Sulakatko, V.; Lill, I.; Witt, E. Methodological Framework to Assess the Significance of External Thermal Insulation Composite System (ETICS) on-site Activities. Energy Procedia 2016, 96, 446-454. [CrossRef]

28. Chan, A.P.C.; Yung, E.H.K.; Lam, P.T.I.; Tam, C.M.; Cheung, S.O. Application of Delphi method in selection of procurement systems for construction projects. Constr. Manag. Econ. 2001, 19, 699-718. [CrossRef]

29. Olson, K. An Examination of Questionnaire Evaluation by Expert Reviewers. Field Methods 2010, 22, $295-318$. [CrossRef]

30. Hallowell, M.R.; Gambatese, J.A. Qualitative Research: Application of the Delphi Method to CEM Research. J. Constr. Eng. Manag. 2010, 136, 99-107. [CrossRef]

31. Ameyaw, E.E.; Hu, Y.; Shan, M.; Chan, A.P.C.; Le, Y. Application of Delphi method in construction engineering and management research: A quantitative perspective. J. Civ. Eng. Manag. 2016, 22, 991-1000. [CrossRef]

32. Chau, W.K. The validity of the triangular distribution assumption in Monte Carlo simulation of construction costs: Empirical evidence from Hong Kong. Constr. Manag. Econ. 1995, 13, 15-21. [CrossRef]

33. Thomas, A.V.; Kalidindi, S.N.; Ganesh, L.S. Modelling and assessment of critical risks in BOT road projects. Constr. Manag. Econ. 2006, 24, 407-424. [CrossRef]

34. Dikmen, I.; Birgonul, M.T.; Ozorhon, B.; Sapci, N.E. Using analytic network process to assess business failure risks of construction firms. Eng. Constr. Archit. Manag. 2010, 17, 369-386. [CrossRef]

35. Skulmoski, G.J.; Hartman, F.T. The Delphi Method for Graduate Research. J. Inf. Technol. Educ. 2007, 6, 1-21. [CrossRef]

36. Rowe, G.; Wright, G. Expert Opinions in Forecasting: The Role of the Delphi Technique. Princ. Forecast. Int. Ser. Oper. Res. Manag. Sci. 2001, 30, 125-144.

37. Powell, C. The Delphi technique: Myths and realities. J. Adv. Nurs. 2003, 41, 376-382. [CrossRef] [PubMed]

38. Sulakatko, V.; Lill, I.; Soekov, E.; Arhipova, R.; Witt, E.; Liisma, E. Towards Nearly Zero-energy Buildings through Analyzing Reasons for Degradation of Facades. Procedia Econ. Financ. 2014, 18, 592-600. [CrossRef]

39. WTA Merkblatt 2-13; Fraunhofer IRB Verlag: Munich, Germany, 2016.

40. ETAG 014 Guideline for European Technical Approval of Plastic Anchors for Fixing of External Thermal Insulation Composite Systems With Rendering; European Organisation for Technical Approvals: Brussels, Belgium, 2002.

41. ETAG 004. Guideline for European Technical Approval of External Thermal Insulation Composite Systems with Rendering; European Organisation for Technical Approvals: Brussels, Belgium, 2013.

42. CEN-EN 13499: 2003 Thermal Insulation Products for Buildings-External Thermal Insulation Composite Systems (ETICS) Based on Expanded Polystyrene-Specification; European Committee for Standardization (CEN): Brussels, Belgium, 2003.

43. CEN-EN 13500: 2004 Thermal Insulation Products for Buildings_External Thermal Insulation Composite Systems (ETICS) Based on Mineral Wool-Specification; European Committee for Standardization (CEN): Brussels, Belgium, 2004.

44. Annila, P.J.; Pakkala, T.A.; Suonketo, J.; Lahdensivu, J. Examining of weather resistance of ETICS with stresses which correspond to weather conditions in Finland. Proc. Int. Conf. Ageing Mater. Struct. 2014, 1, 73-80.

45. Pikkuvirta, J.; Annila, P.J.; Suonketo, J. New test method for wind-driven rain penetration of ETICS 1 Introduction. Proc. Int. Conf. Ageing Mater. Struct. 2014, 1, 134-139.

46. Balayssac, J.P.; Nicot, P.; Ruot, B.; Devs, O.; Détriché, C.H. Influence of admixtures on the cracking sensitivity of mortar layers applied to a mineral substrate. Constr. Build. Mater. 2011, 25, 2828-2836. [CrossRef]

47. Barberousse, H.; Ruot, B.; Yéprémian, C.; Boulon, G. An assessment of façade coatings against colonisation by aerial algae and cyanobacteria. Build. Environ. 2007, 42, 2555-2561. [CrossRef]

48. Barreira, E.; de Freitas, V.P. Experimental study of the hygrothermal behaviour of External Thermal Insulation Composite Systems (ETICS). Build. Environ. 2013, 63, 31-39. [CrossRef]

49. Bochen, J. Study on the microstructure of thin-layer facade plasters of thermal insulating system during artificial weathering. Constr. Build. Mater. 2009, 23, 2559-2566. [CrossRef] 
50. Bochen, J.; Gil, S. Properties of pore structure of thin-layer external plasters under ageing in simulated environment. Constr. Build. Mater. 2009, 23, 2958-2963. [CrossRef]

51. Bochen, J.; Gil, S.; Szwabowski, J. Influence of ageing process on porosity changes of the external plasters. Cem. Concr. Compos. 2005, 27, 769-775. [CrossRef]

52. Collina, A.; Lignola, G.P. The External Thermal Insulation Composite System (ETICS): More than Comfort and Energy Saving. In Proceedings of the 3rd Portuguese Congress on Construction Mortars, Lisbon, Portugal, 2010; Available online: http://www.apfac.pt/congresso2010/comunicacoes/Paper\%2009_2010. pdf (accessed on 20 October 2018).

53. D'Orazioa, M.; Cursioa, G.; Graziania, L.; Aquilantib, L.; Osimanib, A.; Clementib, F.; Yéprémianc, C.; Laricciad, V.; Amoroso, S. Effects of water absorption and surface roughness on the bioreceptivity of ETICS compared to clay bricks. Build. Environ. 2014, 77, 20-28. [CrossRef]

54. Daniotti, B.; Paolini, R. Evolution of Degradation and Decay in Performance of ETICS. In Proceedings of the 11th International Conference on Durability of Building Materials and Components, Istanbul, Turkey, 11-14 May 2008.

55. Holm, A.; Künzel, H.M. Combined effect of temperature and humidity on the deterioration process of insulation materials in ETICS. In Proceedings of the 5th Symposium on Building Physics in the Nordic Countries, Gothenburg, Sweden, 24-26 August 1999.

56. Künzel, H.M.; Gertis, K. Plattenbausanierung durch Außendämmung. Wie wichtig ist die Dampfdurchlässigkeit des Dämmsystems? IBP-Mitteilung 1996, 23, 23-24.

57. Künzel, H.M.; Wieleba, R. Specific building-physical properties of ETICS on mineral-wool basis. In Proceedings of the 4th Congresso Português de de Argamassas e ETICS, Coimbra, Portugal, 2009; Available online: http:/ / www.apfac.pt/congresso2012/comunicacoes/Paper\%20114_2012.pdf (accessed on 26 October 2018).

58. Norvaišiene, R.; Burlingis, A.; Stankevičius, V. Impact of acidic precipitation to ageing of painted facades' rendering. Build. Environ. 2007, 42, 254-262. [CrossRef]

59. Norvaišienè, R.; Griciutè, G.; Bliūdžius, R. The Changes of Moisture Absorption Properties during the Service Life of External Thermal Insulation Composite System. Mater. Sci. 2013, 19, 1-5. [CrossRef]

60. Pakkala, T.; Suonketo, J. Hygrothermal Behaviour Testing of External Thermal Insulation Composite Systems with Rendering in Nordic Climate. In Proceedings of the 12th International Conference on Durability of Building Materials and Components, Porto, Portugal, 15 April 2011.

61. Schrepfer, T. Faserbewehrte Putze auf hochdämmenden Untergründen. Bauphysik 2008, 30, 117-122. [CrossRef]

62. Silva, C.M.; Flores-Colen, I.; Gaspar, S. Numerical analysis of renders' adhesion using an interface model. Constr. Build. Mater. 2013, 38, 292-305. [CrossRef]

63. Simões, N.; Simões, I.; Serra, C.; Tadeu, A. Thermographic inspection of external thermal insulation systems with mechanical fixing. In Proceedings of the SPIE Sensing Technology + Applications, Baltimore, MD, USA, 12 May 2015.

64. Zirkelbach, D.; Holm, A.; Künzel, H. Influence of temperature and relative humidity on the durability of mineral wool in ETICS. In Proceedings of the 10DBMC International Conference On Durability of Building Materials and Components, Lyon, France, 7-20 April 2005.

65. Topcu, D.; Merkel, H. Durability of External Wall Insulation Systems with Extruded Polystyrene Insulation Boards. In Proceedings of the 11th International Conference on Durability of Building Materials and Components, Istanbul, Turkey, 11-14 May 2008.

66. Vallee, F.; Blanchard, N.; Rubaud, M.; Gandini, A. Investigation on the behaviour of polymer-cement composites in ETICS renderings. Durab. Build. Mater. Compon. 1999, 1-4, 1070-1080.

67. Yin, X.; Li, H.; Haitao, B.; Ke, H. Weatherability studies on external insulation thermal system of expanded polystyrene board, polystyrene granule and polyurethane foam. J. Wuhan Univ. Technol. Sci. 2010, 25, 1027-1032. [CrossRef]

68. Barreira, E.; De Freitas, V.P. External thermal insulation composite systems: Critical parameters for surface hygrothermal behaviour. Adv. Mater. Sci. Eng. 2014, 2014. [CrossRef]

69. Barreira, E.; de Freitas, V.P. The effect of nearby obstacles in surface condensations on external thermal insulation composite systems: Experimental and numerical study. J. Build. Phys. 2014, 37, 269-295. [CrossRef] 
70. Barreira, E.; Delgado, J.M.P.Q.; De Freitas, V.P. Biological Defacement of External Thermal Insulation Composite Systems. Hygrothermal Behav. Build. Pathol. Durab. 2013, 1, 113-140.

71. Breuer, K.; Hofbauer, W.; Krueger, N.; Mayer, F.; Scherer, C.; Schwerd, R.; Sedlbauer, K. Wirksamkeit und Dauerhaftigkeit von Bioziden in Bautenbeschichtungen. Bauphysik 2012, 34, 170-182. [CrossRef]

72. Edis, E.; Türkeri, N. Durability of external thermal insulation composite systems in Istanbul Turkey. ITU J Fac. Arch. 2012, 9, 134-148.

73. Flores-Colen, I.; de Brito, J.; Branco, F. In situ adherence evaluation of coating materials. Exp. Tech. 2009, 33, 51-60. [CrossRef]

74. Gaspar, P.L.; de Brito, J. Limit States and Service Life of Cement Renders on Façades. J. Mater. Civ. Eng. 2011, 23, 1396-1404. [CrossRef]

75. Johansson, S.; Wadsö, L.; Sandin, K. Estimation of mould growth levels on rendered façades based on surface relative humidity and surface temperature measurements. Build. Environ. 2010, 45, 1153-1160. [CrossRef]

76. Korjenic, A.; Steuer, R.; Št'Astník, S.; Vala, J.; Bednar, T. Beitrag zur Lösung des Problems der Algenbildung auf Außenwänden mit Wärmedämmverbundsystemen (WDVS). Bauphysik 2009, 31, 343-353. [CrossRef]

77. Künzel, H.M. Austrocknung von Wandkonstruktionen mit Wärmedämm-Verbundsystemen. Bauphysik 1998, 20, 18-23.

78. Künzel, H.M. Außendämmung bei Bestandsbauten Schäden, Ursachen, Instandsetzungen. Schäden Beim Energieeffizienten Bauen 2010, 45, 37-45.

79. Künzel, H.M.; Fitz, C. Bauphysikalische Eigenschaften und Beanspruchung von Putzoberflächen und Anstrichstoffen H. WTA-Schriftenreihe 2004, 49-72. Available online: https://wufi.de/literatur/K\%c3\% bcnzel,\%20Fitz\%20-\%20Bauphysikalische\%20Eigenschaften\%20und\%20Beanspruchung.pdf (accessed on 20 October 2018).

80. Zillig, W.; Lenz, K.; Sedlbauer, K.; Krus, M. Condensation on facades-Influence of construction type and orientation. In Proceedings of the 2nd International Conference on Building Physics, Leuven, Belgium, 14-18 September 2003; pp. 437-444.

81. Rothge, J.; Willis, G.; Forsyth, B. Questionnaire Pretesting Methods: Do Different Techniques and Different Organizations Produce Similar Results? In Proceedings of the Annual Meeting of the American Statistical Association, Atlanda, GA, USA, 5-9 August 2001.

82. Presser, S.; Couper, M.P.; Lessler, J.T.; Martin, E.; Martin, J.; Rothgeb, J.M.; Singer, E. Methods for testing and evaluating survey questions. Public Opin. Q. 2004, 68, 109-130. [CrossRef]

83. Layzell, J.; Ledbetter, S. FMEA applied to cladding systems-Reducing the risk of failure. Build. Res. Inf. 1998, 26, 351-357. [CrossRef]

84. Preston, C.; Coleman, A. Optimal number of response categories in rating scale: Reliability, validity, discriminating power, and responding preferences. Acta Psychol. 2000, 104, 1-15. [CrossRef]

85. European Parliament. Regulation of the European Parliament and of the Council of 9 March 2011 laying down harmonised conditions for the marketing of construction products and repealing Council Directive 89/106/EEC. Off. J. Eur. Union 2011, 305, 43-88.

86. Aurnhammer, H.E. Verfahren zur Bestimmung von Wertminderung bei (Bau-)Mängeln und (Bau-) Schäden. Baurecht 1978, 5, 48-56.

87. O'Gorman, T.W. A comparison of the F-test, Friedman's test, and several aligned rank tests for the analysis of randomized complete blocks. J. Agric. Biol. Environ. Stat. 2001, 6, 367-378. [CrossRef]

88. McCrum-Gardner, E. Which is the correct statistical test to use? Br. J. Oral Maxillofac. Surg. 2008, 46, 38-41. [CrossRef] [PubMed]

89. Madrigal, L.O.; Lanzarote, B.; Bretones, J.M.F. Proposed method of estimating the service life of building envelopes. Rev. Constr. 2015, 14, 60-68.

90. Bowles, J.B.; Peláez, C.E. Fuzzy logic prioritization of failures in a system failure mode, effects and criticality analysis. Reliab. Eng. Syst. Saf. 1995, 50, 203-213. [CrossRef]

(C) 2018 by the authors. Licensee MDPI, Basel, Switzerland. This article is an open access article distributed under the terms and conditions of the Creative Commons Attribution (CC BY) license (http://creativecommons.org/licenses/by/4.0/). 